\title{
The Effect of Mercury on the Feeding Behavior of Fathead Minnows (Pimephales promelas)
}

\author{
Mark Grippo \\ Thesis submitted to the faculty of Virginia Polytechnic Institute \\ And State University in partial fulfillment of the requirements \\ For the degree of \\ Master of Science \\ In \\ Biology \\ Dr. Alan Heath, Chair \\ Dr. Paul A. Angermeier \\ Dr. Thomas A. Jenssen
}

April 13, 2001

Blacksburg, VA

Keywords: Mercury; Foraging Behavior, Learning, Fathead Minnows, Neurotransmitters 


\title{
The Effect of Mercury on the Feeding Behavior of Fathead Minnows (Pimephales promelas)
}

\author{
Mark Grippo
}

\section{(ABSTRACT)}

Fathead minnows (Pimephales promelas) were exposed to mercury $(1.69,6.79$, and 13. $57 \mu \mathrm{g} / \mathrm{l} \mathrm{HgCl}_{2} ; 10 \mathrm{~d}$ exposure) and afterwards tested using various metrics of foraging ability while feeding in a vegetated habitat. Among the foraging metrics were foraging efficiency, capture speed, and the ability to learn and retain information regarding habitat characteristics. Comparisons with control fish and fish from the two highest exposure groups revealed consistent performance deficits in foraging efficiency and capture speed. However, no treatment effects on learning were detected. In determining the underlying proximate cause of the foraging deficits, it is believed that the greater pause time exhibited by treatment fish while foraging was the main cause of treatment differences. In the future, behavioral studies will continue to allow toxicity testing of environmentally relevant variables such as those used by behavioral ecologists. Such tests, when combined with tests of field collected specimens, could prove powerful in linking laboratory toxicity to toxicity in wild populations. 


\section{ACKNOWLEDGMENTS}

I would like to thank my advisor Dr. Alan Heath for giving me freedom in developing my project and for all the helpful suggestions throughout. I would also like to thank my committee members Dr. Paul Angermeier and Dr. Thomas A. Jenssen. The suggestions and ideas they offered were essential to this project. I am also grateful to the laboratory of Dr. Neal Castagnoli for the use of the HPLC, and Jaques Petzer for his aid in the neurotransmitter analysis. 


\section{Table of Contents}

Page

Abstract................................................................ ii

Acknowledgements................................................. iii

List of Tables.................................................... v

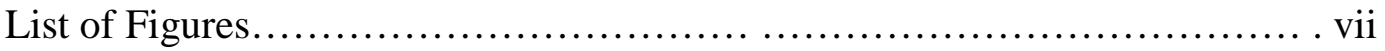

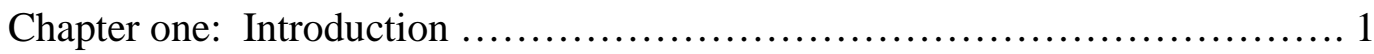

Chapter two: Materials and Methods...................................10

Chapter three: Results............................................ 17

Chapter four: Discussion..........................................29

References.......................................................... 42

Appendix 1: Figures............................................... 55

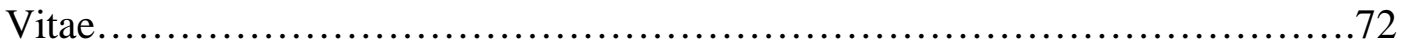


List of Tables

Table 1. Average number of worms eaten per day (Mean \pm SE) during a

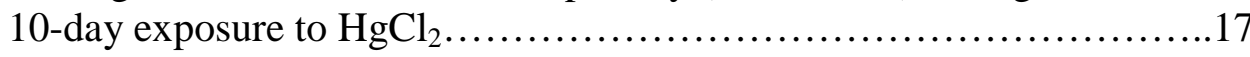

Table 2. Frequency of encountering three and four worms......................19

Table 3. Pause time and quadrant switches per day (Mean \pm SE) .................20

Table 4. Mean daily variance for time to three and four encounters and the treatment variance for the best time measurements......................21

Table 5. Muscle tissue Hg body burden (Mean $\pm \mathrm{SE}$ ) and acetylcholinesterase activity (Mean \pm SE) after a 10-day waterborne exposure to $\mathrm{HgCl}_{2}$, immediately after exposure (pre-trial) and after the 10-day trial period in which exposed fish were held in clean water (post-trial)..............22.

Table 6. Neurotransmitter levels (Mean \pm SE) immediately after a 10 day waterborne exposure to $\mathrm{HgCl}_{2}$, (pre-trial) and after the 10-day trial period in which exposed fish were held in clean water (post-trial)........23

Table 7. Average number of worms eaten per day (Mean \pm SE) during a 10-day exposure to $\mathrm{HgCl}_{2}$

Table 8. Percent of foraging time spent in the high food patch (mean \pm SE of the First two and last two days) during the pre-switch feeding arrangement.....24

Table 9. Percent of first choices per day for the high food patch (mean \pm SE of the first two and last two days) during the pre-switch feeding arrangement..... 25

Table 10. Number of enters (mean \pm SE of the fist two and last two days) into the low food patch during the pre-switch feeding arrangement....25

Table 11. Percent of foraging time spent in the high food patch (mean $\pm \mathrm{SE}$ of the fist two and last two days) during the post-switch feeding arrangement.......26

Table 12. Percent of first choices per day for the high food patch (mean $\pm \mathrm{SE}$ of the fist two and last two days) during the post-switch feeding arrangement......26

Table 13. Number of enters (mean $\pm \mathrm{SE}$ of the fist two and last two days) into the low food patch during the post-switch feeding arrangement. 
List of Tables

Table 14. Muscle tissue $\mathrm{Hg}$ body burden (Mean \pm SE) and acetylcholinesterase activity (Mean $\pm \mathrm{SE}$ ) after a 10-day waterborne exposure to $\mathrm{HgCl}_{2}$, followed by a 10-day behavioral trial during which time the fish were held in clean water.

Table 15. Neurotransmitter levels (Mean \pm SE) immediately after a 10 day waterborne exposure to $\mathrm{HgCl}_{2}$, followed by a 10-day behavioral trial during which time the fish were held in clean water.....................28

Table 16. Average time (Mean \pm SE) spent I feeding area and average number of prey rejections per encounter during the behavioral trials...............30

Table 17 Average (Mean \pm SE) handling time and handling time per capture........32 


\section{List of Figures}

Figure 1 Potential alterations in individuals after exposure to a toxicant 56

Figure 2 Potential ways toxicants can disrupt the various steps leading to prey consumption

Figure 3 Ways in which experience, through learning, influences habitat choice, prey search within the habitat, and prey capture....

Figure 4 Experimental Aquaria. 59

Figure 5 Number of worms encountered by control and treatments after one minute...... 60

Figure 6 Number of worms encountered by control and treatments after two minutes..... 61

Figure 7 Number of worms encountered by control and treatments after three minutes.... 62

Figure 8 Maximum encounters (for 2 and 3 minutes) over the 7-day trial period for each Treatment. 63

Figure 9 Time to three encounters for treatment and controls, over the 7- day trial period.. 64

Figure 10 Time to four encounters for treatment and controls, over the 7- day trial period....65

Figure 11 Shortest time to three and four encounters for each group 66

Figure 12 Performance distribution of control and T 13 for the time to four encounters metric 67. 


\section{List of figures}

Figure 13 Performance distribution of control and $\mathrm{T} 6$ for the time to four encounters metric

Figure 14 The relationship between pause time and time until three worms are

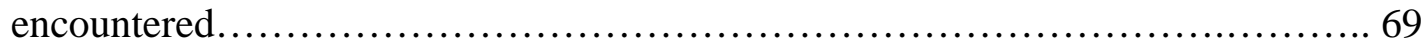

Figure 15 The relationship between pause time and time until three worms are encountered............................................................... 70

Figure 16 Average daily pause time until three and four worms were encountered............ 71 


\section{Chapter One: INTRODUCTION}

In recent years, aquatic toxicologists have recognized the need to move beyond simple acute toxicity tests (in which death is the endpoint) in order to determine the sublethal effects of toxicants on fish. Also, the emergence of ecotoxicology brought fieldwork into toxicology and ecological realism into laboratory toxicity experiments. Ecotoxicology recognizes that within ecosystems there are multiple, interacting levels of organization ranging from the cellular to the ecosystem level. Due to multiple ecosystem linkages, toxicity testing is most informative if test results are placed within an ecosystem context. For example, from a bottom up perspective, the effects of pollutants at the cellular level (e.g. pollutant interactions with enzymes and genetic material) can accumulate and eventually alter the functional integrity of an organ/ tissue system, which potentially affects the life history of the individual. If enough individuals are affected, changes at higher levels of ecosystem organization such as the population and community may result. Ultimately, changes at the community level may affect ecosystem structure (e.g. species abundance and diversity) and function (e.g. nutrient cycling, trophic dynamics). Furthermore, such bottom up pollution affects may lead to top down effects in which individuals not directly harmed by the pollutants are affected by the ecosystem level changes resulting from the pollutants.

There are several ways in which toxicant affect the individual (Fig. 1) such as reduction of growth, reproductive capacity, and metabolite storage, and all have come under investigation. My study focused on nervous system dysfunction and the resulting behavioral manifestations that specifically relate to foraging.

Behavioral toxicology of prey predator prey interactions. Behavioral toxicologists have extensively investigated feeding behavior, because feeding impairment could have repercussions on survivorship, growth, and reproductive capacity. Much preliminary work has focused on appetite suppression, foraging efficiency and predator avoidance (Atchison et. al., 1996; Beitinger, 1990). There is also an extensive literature on toxicants and swimming performance (Little et. al., 1993), an important factor in the

outcome of predator-prey interactions. Research on foraging behavior is often in the 
form of mechanistic studies (Atchison et al., 1996) in which a toxicant's interaction with a specific component of food acquisition is examined (Fig. 2). The mechanistic parameters utilized are the same as those used by behavioral ecologists, such as food consumption rate, feeding attempts, capture efficiency, handling time and reaction distance. A review of research in this area follows.

A variety of pollutants have been found to decrease food consumption. One possible mechanism of appetite suppression is a rise in blood sugar induced by the stress of toxicant exposure. (Heath, 1995). In an early study utilizing live prey, minnow consumption by bluegill decreased in a dose dependent manner during a $114 \mathrm{~d}$ exposure to hydrogen sulfide (Smith, 1976). In a separate study, larval brook trout kept at a $\mathrm{pH}$ of 5.5 attempted fewer strikes at zooplankton than fish in water of pH 7.2 (Cleveland et al., 1986). Suppression of feeding was also found in rainbow trout exposed to tributyl phosphorotrithioate DEF), 2,4,-dichlorophenoxyacetic acid (2,4-DMA), and methyl parathion (Little et al., 1990). Similarly, during a $28 \mathrm{~d}$ exposure, dioxin, at a range of sub-lethal concentrations, reduced feeding in juvenile trout (Mehrle et al., 1988). Larval largemouth bass, exposed to 67 and $88 \mathrm{ug} / \mathrm{L}$ pentachlorophenol (PCP) for their first eight weeks post-hatching, exhibited significantly fewer predacious behaviors toward brine shrimp compared to control fish (Brown, 1987). Food consumption in fish was also decreased by metals such as copper (Sandheinrich and Atchison, 1989), lead (Weber, 1991) and zinc (Farmer et al., 1979), though in the latter study consumption reached control levels in 10 to 20 days depending on treatment concentration. Finger (1985), exposed bluegill to five concentrations of fluorene for thirty days. Fish in all treatment groups consumed fewer chironomid larvae compared to control fish and, in three of the highest concentrations, made fewer strikes at larvae. It is interesting that feeding suppression was found at a fluorene concentration lower than the chronic LOEC, making food consumption, in this study, a more sensitive endpoint than growth. Over all, feeding behavior is an extremely sensitive stress indicator (Beitinger, 1990). There is also strong evidence for toxicant induced feeding suppression in disturbed natural systems. Killifish from a creek polluted with mercury and from an uncontaminated site, when exposed to water from the polluted site, both consumed fewer grass shrimp than reference site fish 
(Smith and Wies, 1997). These authors also reported significant differences between contaminated and reference fish in the frequency of prey capture attempts, with contaminated fish making almost half as many strikes per minute.

Toxicants may also decrease food consumption by decreasing prey capture efficiency. Such a reduction is indicative of possible nervous/ neuromuscular dysfunction. Bluegill exposed to fluorene at concentrations ranging from .06 to $1 \mathrm{mg} / \mathrm{L}$ had, for most treatment groups, a capture efficiency (defined as the number of prey captured/strike) of half the control value (Finger, 1985). Rainbow trout also required more strikes to capture prey when exposed to low concentrations of methyl parathion, PCP, DEF, and carbaryl $(.01 \mathrm{mg} / \mathrm{L}, .2 \mathrm{ug} / \mathrm{L}, 5 \mathrm{ug} / \mathrm{L}$, and $.01 \mathrm{mg} / \mathrm{L}$ respectively) (Little et al., 1990). Brown (1987), using largemouth bass exposed to PCP, found bass exposed to 67 and $88 \mathrm{ug} / \mathrm{L}$ made more mistakes and misses over an eight week period as compared to control and the lowest concentration treatment groups. Mathers (1985) found similar results at $50 \mathrm{ug} / \mathrm{L} \mathrm{PCP}$, as did Weber (1991) with fathead minnows and daphnids. However, capture efficiency is not always a sensitive metric of toxicity. Sandheinrich (1989) exposed bluegill to .5, 31, 80 and $1710 \mathrm{ug} / \mathrm{L}$ copper $(\mathrm{Cu})$ for four days during which time bluegill were allowed to forage on $\mathrm{Cu}$ exposed or unexposed Damselflies (Enallagma sp), amphipods (Hyalella azteca), Daphnia magna and Daphnia pulex. Various foraging parameters were measured. Capture efficiency was found to be significantly lower than controls only when bluegill were preying on unexposed amphipods and large and small damselflies. More recent studies (Bryan et al., 1993) found no decrease in prey capture ability in bluegills foraging on Daphnia. However, in the case of this study, Atchison (1996) suggests that Daphnia may be too easily captured to reveal any impairment of foraging ability.

Handling time is defined as the time between prey capture and the resumption of search and is commonly used as a variable in bioenergetics and optimal foraging models (Mittelbach, 1981; Stephens and Krebs, 1986; Turner and Mittelbach, 1990). Handling time may be particularly sensitive to toxicants that interact with olfactory or gustatory receptors, as damage to these organs would prevent normal sensation of prey (reviewed 
in Heath, 1995; Baatrup, 1991). Examples include sub-lethal concentrations of benzene (Babcock, 1985), Mercury (Hikada, 1970); Rehnberg and Schreck, 1986) and $\mathrm{Cu}$ (Gardner and LaRoche, 1973; Sutterlin and Sutterlin, 1970). Sandheinrich and Atchison (1989) noted that handling times of bluegill exposed to copper increased for a variety of invertebrate prey items. Using optimal foraging models, they theorized that increases in handling time would slow the rate of energy gained while foraging, as well as alter optimal prey size (Sandheinrich and Atchison, 1990). An increase in handling time was also found by Nyman (1981), when exposing zebra fish to lead. In contrast, Bryan et al., (1993) found that cadmium had no effect on the handling time of bluegill foraging on Daphnia.

Another important component of foraging is reaction distance, or the greatest distance at which a fish can detect a prey item. Reaction distance increases with age (Hairston et al., 1983) and size (Walton et al., 1997) and, consequently, is important in determining foraging strategy and diet composition in the early life stages of fish (O' Brien et al., 1976; 1989; Werner and Hall, 1974; Eggers, 1977). Using midge larvae as a prey item, the reaction distance of bluegill exposed to $1 \mathrm{mg} / \mathrm{L}$ of fluorene was half that of control fish (Finger, 1985). During a $14 \mathrm{~d}$ exposure to 100ug/L lead, zebrafish feeding on Daphnia also had significantly shorter reaction distances compared to controls. However, copper had no effect on the reaction distance of bluegill to Daphnia (Sandheinrich and Atchison, 1989) even though copper can damage the cornea of fish (Bodammer, 1983).

Toxicants may potentially decrease foraging success by impairing other sensory organs as well. An example is the lateral line system, valuable for foraging in turbid environments, which is made hypersensitive by DDT (Heath, 1995).

Swim performance is another important factor in foraging. Performance tests often measure critical swimming speed (maximum speed attainable), swimming capacity (ability of the fish to maintain its position against water flow) and swimming activity (a measure of spontaneous movement). Various metals and organic pollutants have been 
found to alter swimming behavior by a number of toxicant specific mechanisms including simple irritation, reduction in oxygen uptake or alteration in nervous function and tissue metabolism (Heath, 1995). On the whole, swimming ability is a sensitive indicator of toxic stress but the nature of the effect is dependent on the exposure regime. For example, cadmium and chromium (Ellgard et al., 1978) have been found to induce hyperactivity. However, Little (1990) exposed rainbow trout to carbaryl, chlordane, 2,4,DMA, DEF, methyl Parathion, and PCP, all at sub-lethal concentrations, for $96 \mathrm{~h}$ and found that all decreased spontaneous swimming. In the same study, when swimming capacity was measured, DEF and 2,4-DMA caused a slight but significant increase at the lowest concentration and a decrease at higher concentrations. Carbaryl decreased swim capacity only at the highest concentration. A similar series of experiments was performed using larval striped bass and fathead minnows exposed for $96 \mathrm{~h}$ to parathion, carbofuran and molinate. Larvae were exposed to the toxins at half the 96h LC50 and at a concentration found in local rice field drainage basins. Using a test which assessed prolonged and burst swimming, they found, for striped bass, molinate decreased swim capacity at half the a 96h LC50. Larvae were even more sensitive to methyl parathion which decreased capacity at both concentrations (Heath et al., 1993). Fathead minnows suffered swimming impairment upon exposure to carbofuran and molinate (Heath et al., 1997). Sub-lethal concentrations of crude oil (Thomas and Rice, 1985) and DDT (Besch et al., 1977) also were reported to decreased swim capacity.

Finally, though behavioral toxicologists have investigated several ways pollutants can affect foraging behavior (e.g. sensory deficits, swim performance, capture efficiency) there are other potential routes that remain unexamined. One example that was central to this study is the area of learning and foraging behavior.

Learning and foraging behavior. Numerous studies have (reviewed in Hughes et al., 1992) confirmed the importance of experience to foraging success (Fig. 3). For example, handling time, prey recognition (Colgan et al., 1986; Croy and Hughes, 1991) and capture efficiency (Rata \& Nuutingen, 1986) all improve with experience. Learning is also valuable for choosing among habitats with differing food values. By choosing the 
most profitable habitat, fish will not only increase food consumption per unit of foraging time, but also reduce time and energy traveling between patches (Hughes, 1992). Decision making is also important in predator prey relationships. choice of habitat is often influenced by predation risk in that small fish, when threatened by predators, will choose habitats that offer high shelter value but less foraging return (Gotceitas \& Colgan, 1989; Gotceitas, 1990; Mittelbach, 1981; Werner and Hall, 1988).

The studies just described are all relevant to ecotoxicology, and yet, learning and decision making are relatively unexplored by behavioral toxicologists. The few existing studies have shown that contaminants can inhibit a variety of learned responses. For example, experiments with metals showed a fairly consistent impairment of learning and a decrease in the retention time of the learned behavior. In a number of early investigations, fish were trained with classical conditioning techniques to show a light avoidance response, and then exposed to a toxicant. Weir and Hine (1970) exposed conditioned goldfish, in separate trials, to arsenic, lead, mercury and selenium for 24 or 48 hours. For all metals, exposure was associated with decrease retention times. Other studies have confirmed the negative effect of mercury, a well known neurotoxin, on learning (Hartman, 1978) and retention (Salzinger et al., 1973). As an aside, the capacity for learning and retention in amphibians also seems to be affected by metals. Strickler-Shaw and Taylor (1991) found tadpoles exposed to lead levels of .625 mg/l showed a diminished avoidance response to shock stimuli in both learning and retention tests.

Organic pollutants may also impact learning. Several studies have been done using DDT as the toxicant. DDT at $10 \%$ of the $96 \mathrm{~h} \mathrm{LC50} \mathrm{was} \mathrm{found} \mathrm{to} \mathrm{have} \mathrm{no} \mathrm{effect}$ on learning, while exposure to the 96 h LC50 concentration actually increased learning rate (Hatfield and Johansen, 1972). McNicholl and Mackey (1975) found similar results in that rainbow trout fed $100 \%$ of the $96 \mathrm{~h}$ LC 50 dose of DDT exhibited an increase learning rate in subsequent light avoidance conditioning trials. One percent and $10 \%$ of this concentration had no effect on learning. Other organics can also affect learning. In contrast to the variable effects of DDT (which disrupts the $\mathrm{Na} / \mathrm{K}$ ATPase), the 
organophosphate insecticides (acetylcholinesterase inhibitors) have consistently been shown to retard learning in fish. Among them, abate and fenitrothion diminished learning rates of Atlantic salmon (Hatfield and Johanson, 1972), and parathion at 100 $\mathrm{ug} / \mathrm{L}$ inhibited learning in a post exposure conditioning experiment (Sun and Taylor, 1983). However, in the former study impairment occurred at the full $96 \mathrm{~h} \mathrm{LC} \mathrm{50,} \mathrm{with}$ recovery after 7 days in uncontaminated water

As noted above, most experiments done to date involving learning are somewhat artificial. Very few have examined the impairment of ecologically relevant, learned behaviors such as behaviors related to foraging efficiency. Also, exposure is generally brief and artificially high in dose, whereas, in a natural setting, fish would be required to learn while living in a polluted environment. Also, Atchison et al., (1987) commented that many feeding studies were conducted in unstructured environments using dead prey. Heath (1995) has emphasized the difficulty of drawing ecologically relevant conclusions from these past studies.

Research needs in behavioral toxicology. It is evident that many facets of foraging behavior that are well studied by behavioral ecologists are, as yet, unexplored by toxicologists. This is particularly true of learning and decision making, even though such investigations would provide needed insight into the subtle ways pollution can harm ecosystems. To this end, the objective of my project is to investigate behavioral alterations in toxicant exposed fish using foraging experiments that test prey location ability, prey search strategy and habitat choice.

Experimental objectives. Improvement in predation skills is not only a function of physiological developments but also experience (Colgan et al., 1986; Paszkowski and Olla, 1985). Foraging efficiency (amount of food captured/ unit time) improves over time when fish are exposed to a novel food or habitat situation (Werner and Hall, 1981; Hughes, et al., 1992). Though species may have a characteristic search pattern, experience may modify that pattern (e.g. changes in hover time, distance moved between hovers) based on habitat structure (open water vs vegetated; Ehlinger, 1989) or prey type. 
Due to the potential importance of foraging strategies in maximizing energy return, an observational study was made comparing, through time, the foraging behavior and the foraging ability of toxicant exposed and unexposed fish introduced to a novel habitat. It is hypothesized that exposed fish will exhibit deficits in daily measurements of foraging ability compared to control fish, and that treatment fish will show little improvement in foraging success over trial days. Furthermore, in order to relate foraging deficits to behavior, behavior while foraging will be characterized and examined for treatment differences.

Similarly, experience influences not only foraging success but also habitat choice. Fish are capable of determining over time the relative profitability of different habitats and choosing among them based on this learned information as demonstrated in a number of laboratory studies (Warburton, 1990; Ehlinger, 1989, 1990; Gotceitas, 1990). Though habitat quality may change over a span of time, foraging success would be enhanced by a short-term retention of habitat information, so any inhibition of retention due to pollution exposure should be investigated. Consequently, a second experiment examined whether contaminants inhibit or retard the ability of fish to learn and retain information on which habitats offer the greatest foraging return. Toxicant exposure was hypothesized to impair the learning of habitat information, resulting in treatment related differences in habitat use. Specifically, it was hypothesized that during foraging trials the treatment fish would show no preferences between patches of high and low food value. It was also hypothesized that, based on various metrics of retention, exposed fish would show no evidence of retention of habitat information across trial days.

Neurotransmitters and behavior. A variety of fish behaviors are influenced by neurotransmitters (Weber, 1994), making toxicant-neurotransmitter interaction an important area of study. Though several studies have examined the effect of organic and inorganic pollutants on neurotransmitters (reviewed in Weber, 1994) few looked at behavior as well. Therefore, the effect of the toxicant on several neurotransmitters was investigated in order to determine a correlation between exposure, neurotransmitter levels and any behavioral alterations. 
Specifically, acetylcholinesterase (AChE) activity was measured in axial muscle tissue while, norepinephrine (NE), serotonin (5-HT), dopamine (DA), and its metabolite L-DOPA were measured in brain tissue. All of these neurotransmitters are involved variously with locomotion, conditioned responses, and feeding (Smith, 1984), and AChE activity is a commonly used biomarker of pollution stress. A suite of contaminants can inhibit the function of $\mathrm{AChE}$, therefore it is hypothesized that the toxicant exposed fish in this study would have lower AChE activity levels than non-exposed fish. The effect of pollutants on NE, 5-HT, DA and L-Dopa is toxicant-specific and highly variable, making any preliminary hypotheses difficult. Therefore, the purpose of measuring NE, 5-HT, DA and L-DOPA was to investigate the nature of their interaction with mercury. 


\section{Chapter Two: MATERIALS AND METHODS}

\section{General}

Test organisms. Fathead minnows (Pimaphales promelas) were used as test organisms for several reasons. Ecotoxicological studies of fathead minnows are of potentially great importance, as they have a wide distribution throughout the mid-western states. In addition, they are a designated Environmental Protection Agency (EPA) toxicity test fish.

Fathead minnows are characterized as benthic and mid-level water column feeders (Jenkins and Burkehead, 1994). The juvenile fathead minnows (3.5-4.0 cm) were obtained from Aquatox (AR, USA) and Aquatic Biosystems Inc. (CO, USA). Prior to experiments, they were held in Minnow Cool tanks and fed a diet of trout chow.

Blackworms (Tubificidae spp) from a local pet store were used as prey items during experimental trials.

Toxicant For my study, mercury $(\mathrm{Hg})$ was chosen as toxicant based partially on the probability of its having behavioral effects. In mammals, mercury (Cavanagh, 1977), commonly pass the blood brain barrier causing dysfunction by increasing cell membrane permeability (Chang, 1979). In the mammalian CNS, inorganic and organic $\mathrm{Hg}$ damage is to small cortical cells (including those of the visual cortex) and the hippocampus,a primary center for learning and memory (Cavenagh, 1977; Chang, 1979). The neurons of the peripheral nervous system are also subject to damage especially the dorsal root fibers, which are demyelinated (Chang, 1977)

Mercury is also prevalent in the environment (Wiener and Spry, 1996). For example, in Virginia, two prominent examples of mercury contaminated sites are the South River and the North Fork of the Holston River both of which are under fish consumption restrictions for humans. 
Before assignment to a treatment, each fish was anesthetized using Finquel (tricane methanesulfonate) and its length and body weight determined. Fish were exposed to mercury $(1.69,6.79$, or $13.57 \mu \mathrm{g} / \mathrm{l})$ as mercuric chloride $\left(\mathrm{HgCl}_{2}\right)$ using static systems (28 $\mathrm{L}$ aquarium) with all aquariums receiving a daily $50 \%$ water change. Low sub-lethal exposure concentrations were chosen so that treatment fish would not exhibit gross behavioral abnormalities. Also, the exposure levels used in my experiment, while higher than those generally found in the environment, produced environmentally realistic body burdens of mercury (Weiner and Spry, 1996).

Experimental habitats. Two separate experiments were performed, each using a different habitat in which to test the fish (Fig. 4 a \& b). For the first experiment, the habitat (habitat 1) consisted of one large patch of artificial vegetation $(35 \mathrm{~cm} \mathrm{X} 42 \mathrm{~cm}$; feeding area was $13 \mathrm{~cm}$ in depth), while the habitat for the second series of experiments (habitat 2) contained two patches of equal size $(35 \mathrm{~cm} \mathrm{X} 12 \mathrm{~cm})$ and density of artificial vegetation separated by a sandy area. In both experiments, separated from the feeding area was an open water space into which fish could be transferred. The artificial vegetation consisted of $9 \mathrm{~cm}$ plastic sticks attached to a plastic mesh plate, which was covered in white dolomite sand.

\section{Foraging trials}

Protocol for experiment one. An entire 20-day run entailed an initial exposure to one of three $\mathrm{HgCl}_{2}$ treatments in the $28 \mathrm{~L}$ holding tanks for 10 days and then transfer to noncontaminated aquaria at which time the seven day foraging trials began. Foraging trials were followed by a four-day, post-trial appetite study. A fourth group was unexposed and served as the control. Four total runs (blocks) were made. Each experimental run utilized a completely randomized design with two tanks (replicates) per treatment (eight tanks total). Within each holding tank, three fish (sub-samples) were housed singly in three separate, gated, removable compartments for a total of 24 fish (six fish/ sample; three treatments and a control). The treatment and control groups used in the trials will be referred to by their exposure concentration (i.e. T1, T6, T13 or control). Also, each holding tank held two additional fish, housed separately. These fish, referred to as "non- 
experimental fish", were used for biochemistry tests immediately after the initial 10-day exposure and did not undergo the training or foraging experiments mentioned below. The purpose of the non-experimental fish was to allow a biochemical comparison between fish immediately after $\mathrm{HgCl}_{2}$ exposure and after the 10 day trial period in which the fish had been held in non-contaminated water.

Before the foraging trials began, it was necessary that each fish be trained to readily enter the feeding area of the experimental aquarium. Therefore, during the initial 10-day exposure period each fish was individually removed from its holding tank (it remained in its compartment), transferred to the experimental aquarium, the gate removed and the fish allowed to feed on 12 dead, unburied blackworms for five minutes. The feeding area contained no artificial vegetation, just sand. At the end of the five minutes the fish was led back into the removable compartment and placed in it's holding tank. Feeding activity was videotaped and the number of worms consumed was recorded. This training was repeated daily from the fourth to the tenth day of the 10-day exposure. These data yielded information on the extent, if any, of appetite suppression brought on by the Hg. After the 10-day exposure, the non-experimental fish were frozen in liquid nitrogen and stored at $-70^{\circ} \mathrm{C}$ for biochemical analysis. The 24 trained fish were transferred to clean water and the foraging trials began.

As noted above, the foraging trial utilized habitat 1 and was designed to assess treatment differences in foraging efficiency, through time, upon exposure to a novel, vegetated habitat. The daily experimental trials began by equally distributing 12 dead, partially buried black worms (so as to increase the difficulty of prey encounter and to lessen visual cues) in the vegetated habitat. A single fish was then placed in the experimental aquarium in the manner described above. To start the feeding trial, the compartment gate was lifted and the fish allowed entrance to the feeding area for 5 minutes. This procedure was repeated for all fish for a total of 24 trials per day. The order in which fish feed was randomized daily. All remaining prey were counted after completion of each trial. The daily trials were repeated for 7 days, a time period deemed sufficient, based on preliminary studies, to maximize foraging efficiency. After 7 days, 
all fish underwent another appetite study (four days) using the protocol from the first 10 days (fish continued to be held in clean water).

From video analysis, the number and time of prey capture were recorded, as were the number and duration of pauses. Also, to characterize movement during the trial, the video monitor screen was divided evenly into quadrants and the number of visits to each quadrant was recorded. From these data, foraging efficiency over time could be monitored along with differences in movement/ search strategy. All fish were initially naïve to the habitat structure and prey placement. Therefore, improvement in foraging efficiency for each group of fish could be compared over time.

Protocol for experiment two. The foraging trials utilizing habitat two were designed to test the ability of treatment fish to learn the relative food availability of each patch. This series of experiments consists of two runs (blocks) with each block consisting of a completely randomized design with two replications in the first block and three replications in the second block. The same four treatment exposure concentrations that were used in experiment one were used in experiment two. Each aquarium contained one removable compartment containing three fish. Fish were exposed for 10 days and simultaneously trained to enter the feeding area in the manner described for experiment one (no vegetation in feeding area), with the exception that fish fed in groups of three with 36 unburied worms in the feeding area rather than 12 . The fish were transferred to clean water and the foraging trials initiated.

The trials began by partially burying 22 blackworms in one patch (high food density) and four in the other (low food density). The minnow compartments were then placed in the experimental aquarium. To ensure the entire habitat could be sampled, the fish were allowed to forage for 10 minutes. This procedure was repeated for all treatment tanks for 6 days. On the seventh day, the relative food values of each patch were switched and the fish monitored for changes in habitat use. Hence, the first 6 days will be referred to as the pre-switch period and time period after the switch will be the postswitch period. Relative food values were switched in order to determine how fish from 
different treatments responded to changes in environmental conditions. As in experiment one, the order in which the fish fed was randomized daily.

From video analysis, the following data were recorded: the total time fish were found in each patch, the first patch sampled and the number of visits to and exits from each patch. In order to minimize the effects of patch depletion on patch residence times, only the first two minutes of the trial were used. Using the time spent in a patch, inferences were made about relative patch preference. The first choice and visit data were used to determine whether the habitat information learned from previous trials was retained. For example, over the 6- day trial period, an increase in the time spent in the profitable patch was considered indicative of learning. Similarly, because repeated visits to the low food patch would be an inefficient use of time, a decrease in visits to the less profitable habitat was also considered evidence of learning. Entering the high food patch first and not visiting the low food patch was considered evidence of retention.

\section{$\underline{\text { Biochemical analysis }}$}

For experiments 1 and 2, at the end of each run, experimental fish were frozen in liquid nitrogen. After thawing, brains were removed for neurotransmitter determinations. Samples of muscle tissue were also taken for use in the determination of $\mathrm{Hg}$ body burden and AChE activity. All samples were stored at $-70^{\circ} \mathrm{C}$ until analysis.

Mercury analytical methods. The mercury species was mercuric chloride (.1 M) obtained from Fisher scientific. Holding tank $\mathrm{Hg}$ levels were measured periodically (approximately every $2^{\text {nd }}$ day) using a Perkin-Elmer MA50 cold vapor atomic absorption spectrophotometer (CVAAS) as described in EPA method 7470 (U.S. EPA, 1990).

Specifically, $100 \mathrm{ml}$ of treatment water was collected and immediately transferred to a biological oxygen demand (BOD) bottle. To each sample $5 \mathrm{ml}$ of $\mathrm{H}_{2} \mathrm{SO}_{4}$ and $2.5 \mathrm{ml}$ of $\mathrm{HNO}_{3}$ (both Fisher trace metal grade) were added followed by $10 \mathrm{ml}$ of $\mathrm{KPO}_{4}$. The samples were digested at $97^{\circ} \mathrm{C}$ in a water bath for $90 \mathrm{~min}$ and allowed to sit overnight. Five $\mathrm{ml}$ of $\mathrm{NaCl}$ hydroxylamine sulfate were added to eliminate excess permanganate. After 15-20 minutes five $\mathrm{ml}$ of stannous chloride were added to a sample and the sample 
was immediately attached to the CVAA.

Mercury body burden. Weighed muscle tissue was digested in $5 \mathrm{ml}$ of concentrated $\mathrm{H}_{2} \mathrm{SO}_{4}$ and $2.5 \mathrm{ml}$ of concentrated $\mathrm{HNO}_{3}$ for $1 \mathrm{hr}$ in a $58^{\circ} \mathrm{C}$ water bath. After cooling on ice, $15 \mathrm{ml}$ of $\mathrm{KPO}_{4}$ were added and the samples left overnight. Before reading the samples, $\mathrm{NaCl}$ hydroxylamine sulfate was added followed by $5 \mathrm{ml}$ of stannous chloride. For each batch of 9 samples, a tissue spike and spike blanks were prepared and analyzed for percent recovery.

Acetylcholinesterase activity. Weighed tissue samples were added to $\mathrm{pH} 8$ phosphate buffer solution and homogenized using a Biospecs tissue tearer. After homogenization the samples were centrifuged at $10,000 \mathrm{rpm}$ for $10 \mathrm{~min}$. AChE activity was then analyzed using a colorimetric method described by Elman et al., (1961) using a Bausch and Lomb 710 spectrophotometer.

Neurotransmitter analysis. Brains were thawed and homogenized in $.05 \mathrm{M}$ perchloric acid spiked with dihydroxybenzylamine as an internal standard. Following centrifugation, neutotransmitter concentrations in the supernatant were measured by high performance liquid chromatography (HPLC) using a modified method of Salzman et al., (1985). The mobile phase consisted of citric acid $(7.0 \mathrm{mM})$, dibasic sodium phosphate (11.5 mM), sodium octylsufate $(.43 \mathrm{mM})$, EDTA $(1.3 \mathrm{mM})$ and diethylamime $(.12 \%)$ with the final solution adjusted to a $\mathrm{pH}$ of 3.5 with HPLC grade phosphoric acid. Using this mobile phase each brain sample took approximately 40 minutes. Samples were analyzed with a BAS, Inc. HPLC system with a LC-18 reversed phase column $(7.5 \mathrm{~cm} \mathrm{x}$ $4 \mathrm{~mm}$ i.d., with $3 \mu \mathrm{m}$ particles) and electrochemical detection. From chromatograms the following neurotransmitter concentrations were determined: norepinephrine (NE), L dopa, dopamine (DA), and serotonin (5-HT).

Statistical analysis. Data were analyzed using the Statistical Analysis System (SAS version 7 1998, Cary, NC). Daily treatment comparisons were performed with the PROC Mixed Function for repeated measures experiments. Non-time dependent comparisons 
were made with Student-Neuman-Keul's test in PROC GLM. This procedure was used rather than a Tukey test in order to decrease the probability of a type II error. Tukey tests were used for all biochemical analyses because biochemical data showed lower variances than behavioral data. For experiment two, unless otherwise noted habitat usage was compared using Student t- tests with SAS PROC UNIVARIATE. For all tests, significance was reported if $\mathrm{p}<.05$. 


\section{Chapter Three: RESULTS}

Experiment one. The pre- and post-trial appetite studies (i.e. the studies that took place before and after the experimental foraging trials in non-vegetated habitats) revealed no significant differences between groups in the number of worms eaten per day (Table 1).

Table 1. Average number of worms eaten per day (mean \pm SE) during 10-day exposure to $\mathrm{HgCl}$. Each value represents the treatment average of the average number of worms consumed/day by an individual fish. Before statistical comparison, post-trial data were $\log$ transformed for equal variance.

\begin{tabular}{lcc}
\multirow{2}{*}{$\begin{array}{l}\text { Exposure } \\
\text { Conc }(\mu \mathrm{g} / \mathrm{L})\end{array}$} & \\
\hline & Worms consumed (number/day) \\
\cline { 2 - 3 } & Pre-trial & Post-trial \\
\hline Control & $4.5 \pm 0.69$ & $6.8 \pm 0.80$ \\
1.69 & $5.5 \pm 0.56$ & $7.8 \pm 0.66$ \\
6.79 & $5.3 \pm 0.56$ & $6.0 \pm 0.46$ \\
13.57 & $4.1 \pm 0.45$ & $5.7 \pm 0.63$ \\
\hline
\end{tabular}

Using the foraging trial data, the number of worms encountered by each group was compared using the first, second (first minute plus the following minute), and third minute (first two minutes plus the following minute) of the trial. These metrics gave an indication of the foraging efficiency (prey captured/ min) over trial time. For most groups, improvement over time occurred until the $3^{\text {rd }}$ or $4^{\text {th }}$ day after which there was a leveling off in performance. Depending on day and treatment, significant differences from controls were found (Fig. 5-7). In the first minute, across the trial days, Control fish show greater mean foraging efficiencies compared to all treatment groups. Controls encountered significantly more worms than $\mathrm{T} 6$ on the $3^{\text {rd }}$ day $(\mathrm{p}<.05)$ and more than $\mathrm{T}$ 13 on the $3^{\text {rd }}(\mathrm{p}<.01), 4^{\text {th }}(\mathrm{p}<.05)$ and $6^{\text {th }}(\mathrm{p}<.01)$ day (Fig. 5). The second minute yielded similar trends (Fig. 6). Control groups encountered significantly more worms than $\mathrm{T} 13$ on the $2^{\text {rd }}(\mathrm{p}<.05)$ day and more than $\mathrm{T} 6$ and $\mathrm{T} 13$ on the $3^{\text {rd }}$ day $(\mathrm{p}=.05 ; \mathrm{p}$ $<.01)$. Treatment effects were also conspicuous into the $3^{\text {rd }}$ minute of the trial showing consistency of treatment effects across trial time (Fig. 7). Across the trial days, Control 
fish show greater mean foraging efficiencies compared to all treatment groups. Significant differences existed on day two (control vs. T 6, $\mathrm{p}<.05$; control vs $\mathrm{T} 13$ $\mathrm{p}<.01$ ), day three (control vs T 13, $\mathrm{p}<.005$ ) and day six (control vs. T 6, $\mathrm{p}<.05$ ).

Prey encounter rates were quite variable within treatments and among days making it difficult to gauge the potential foraging ability of individuals. Consequently, for each trial minute, it is useful to look at the greatest number of worms encountered, or maximum foraging efficiency, across the entire seven- day trial period. A maximum encounter value was determined by averaging the two best performances for a single fish. Treatment comparisons were then performed using the SNK multiple comparison procedure (Zar, 1996). A comparison of the two minute of the trial (Fig. 8) does reveal a significant difference between controls and $\mathrm{T} 13(\mathrm{p}<.05)$ and significant differences again at 3 min (Fig. 5; control vs. T 13, p<.05).

Another, more precise, measurement of foraging ability was the time it took a fish to encounter a certain number of prey items. This metric is a measure of encounter speed and has better resolution than foraging efficiency. In order to include in the analysis as many days and groups as possible, the latency times to three and four encounters were used. For all statistical analysis, data were log transformed for equal variance. The time to three encounters was significantly related to trial days for all treatments except $\mathrm{T} 13$ (control, $\mathrm{p}<=.0001 ; \mathrm{T} 1, \mathrm{p}<.01 ; \mathrm{T} 6, \mathrm{p}=.01$ ) indicating the performance of T 13 did not improve over time (Fig. 9). Mean differences in the encounter speed existed across the seven day trial period with controls showing faster encounter speed compared to exposed groups. On day three, T 6 and T 13 took significantly longer time to find three worms than control fish $(\mathrm{p}<.01, \mathrm{p}=.001$ for T6 and $\mathrm{T}$ 13, respectively). On day seven control fish were significantly faster than all treatment groups (control vs. T1, p=.01; vs. T 6, p<.05; vs. T 13, p<.01).

Control fish had consistently lower mean times to four encounters compared to treatment fish (Fig. 10). However, a significant treatment effect was found only on day three. Compared to control, for day three, T $6(\mathrm{p}<.01)$, and T $13(\mathrm{p}=.01)$ exhibited longer 
encounter times. A significant relationship between time to four encounters and trial day was only found for Control $(\mathrm{p}<.05)$. T1, T 6 and $\mathrm{T} 13$ showed no significant improvement over trial days.

Several fish failed to encounter three or four worms and were not used in the above analysis. Because no number could be assigned to these fish a separate table showing the frequency of successfully encountering three or four worms was made (Table 2). Rarely did more than $75 \%$ of fish in T13 succeed in encountering four worms.

Table 2 Frequency of encountering three and four worms. Fish foraging less than $90 \mathrm{sec}$ were not included in the frequency table.

\begin{tabular}{lccccccccc}
\multicolumn{1}{c}{ Treatment } \\
\cline { 1 - 7 } Day & C & T 1 & T 6 & T 13 & C & T 1 & T 6 & T 13 \\
\hline 1 & 0.95 & 0.81 & 0.86 & 0.71 & & 0.67 & 0.62 & 0.48 & 0.62 \\
2 & 0.95 & 0.95 & 0.96 & 0.87 & 0.86 & 0.86 & 0.74 & 0.61 \\
3 & 1.00 & 1.00 & 0.82 & 0.95 & 0.91 & 0.85 & 0.68 & 0.73 \\
4 & 0.91 & 1.00 & 0.91 & 0.80 & 0.86 & 0.95 & 0.91 & 0.65 \\
5 & 1.00 & 0.95 & 1.00 & 0.91 & & 1.00 & 0.95 & 0.91 & 0.74 \\
6 & 0.86 & 1.00 & 0.95 & 0.86 & 0.86 & 0.90 & 0.86 & 0.71 \\
7 & 0.89 & 1.00 & 0.89 & 0.95 & 0.89 & 1.00 & 0.68 & 0.84 \\
Avg & 0.94 & 0.96 & 0.91 & 0.87 & & 0.86 & 0.88 & 0.75 & 0.70
\end{tabular}

As with foraging efficiency, an average of the "best performance" over the 7-day period was calculated. In this case the two shortest times to three or four encounters were used. The encounter times were inversely related to exposure concentration (Fig. 11). T 13 fish took significantly longer than controls in encountering three prey items $(p<.05)$. T 6 fish compared unfavorably to controls as well. In the time it took to encounter four worms, both T 6 and T 13 fish took significantly longer than control fish (Fig. 11; p=.05 and .01 respectively). 
Controls paused less than T 6 and T 13, but only T 13 was significantly different (Table $3 ; \mathrm{p}<.05$ ). The number of quadrant switches did not differ significantly though treatment means indicate that controls tended to move about the feeding area more than the other groups.

Table 3. Pause time and quadrant switches per day (mean \pm SE) during first three minutes of the foraging trials. Each value represents the treatment average of the average number/ day for an individual fish. An $(*)$ indicates a significant difference $(\mathrm{p}<.05)$.

\begin{tabular}{lcc}
\hline $\begin{array}{c}\text { Exposure conc. } \\
(\mu \mathrm{g} / \mathrm{L})\end{array}$ & $\begin{array}{c}\text { Pause } \\
\text { time }(\mathrm{sec})\end{array}$ & $\begin{array}{c}\text { number of } \\
\text { switches }\end{array}$ \\
\hline Control & $43.98 \pm 6.51$ & $10.40 \pm 1.71$ \\
1.69 & $46.26 \pm 6.67$ & $7.79 \pm 0.96$ \\
6.79 & $59.72 \pm 6.90$ & $7.14 \pm 1.14$ \\
13.57 & $66.57 \pm 6.34 *$ & $5.90 \pm 0.73$ \\
\hline
\end{tabular}

For the more specific endpoints (those measurements whose units are seconds such as time to 3 or 4 captures and pause time) there was a greater variance in the highest exposure treatment groups. Table 4 contains the variance for several of the endpoints mentioned.

The comparatively higher variance in T 6 and T 13 brought up the question of whether the treatment means were being skewed by a small group of heavily impaired individuals or whether the $\mathrm{Hg}$ had an equal effect on all treated fish. To investigate further, the mean time for control, T 6 and T13 to encounter four worms was calculated for each fish using the last 4 trial days, for this was sufficient time to become familiar with the habitat. With each treatment, individuals were then placed into one of eleven groups according to mean performance time. For example, group one consisted of fish whose average time to four encounters fell between 1and 20 seconds; group 2 would be those with scores between 21 and 40 seconds, until all fish were assigned to a group. The frequency distributions for control fish and T 13 differed significant (Kolmogorov- 
Table. 4 The mean daily variance for time to three and four encounters and the treatment variance for the best time measurement. Means are calculated using the treatment variance for each of the seven days.

\begin{tabular}{lcccr}
$\begin{array}{l}\text { Variance } \\
\begin{array}{l}\text { Exposure } \\
\text { Conc }(\mu \mathrm{g} / \mathrm{L})\end{array}\end{array}$ & $\begin{array}{c}\text { Three } \\
\text { encounters }\end{array}$ & $\begin{array}{c}\text { Four } \\
\text { encounters }\end{array}$ & $\begin{array}{c}\text { Best time to } \\
\text { three encounters }\end{array}$ & $\begin{array}{c}\text { Best time to } \\
\text { four encounters }\end{array}$ \\
\hline Control & 1478.6 & 2579.7 & 460.9 & 1384.7 \\
1.69 & 1982.7 & 3617.9 & 260.2 & 1094.3 \\
6.79 & 3341.8 & 4498.7 & 765.1 & 2058.7 \\
13.57 & 3179.9 & 3896.1 & 1913.5 & 2459.4 \\
\hline
\end{tabular}

Smirnov goodness of fit test; $\mathrm{p}<.05)$. Compared to controls, $\mathrm{T} 13$ has a much greater spread of performance times (Fig. 12). One can see, comparatively, a smaller group of high to moderate performers (those below $100 \mathrm{sec}$ ) and a larger group of low performers (those above $140 \mathrm{sec}$ ). This suggests that most fish were affected by the exposure, but not all were affected equally. In fact, some (those under $60 \mathrm{sec}$ ) compared favorably with controls. The distribution of T 6 fish had a similar pattern (Fig. 13), and the distribution was also significantly different (Kolmogorov-Smirnov goodness of fit test; $\mathrm{p}<.05)$.

Biochemical analysis for exp 1. The post- trial fish had 10 days in clean water but appeared to depurate very little $\mathrm{Hg}$ in that time period, as tissue concentrations remained quite similar (Table 5). AChE activity was not found to differ significantly with treatment in pre or post foraging trial tests. $\mathrm{T} 1$ fish did have elevated, but nonsignificant, activity in the pre-trial measurement (Table 5).

Similar results were found for neurotransmitter levels (Table 6). T13 fish had significantly lower 5-HT levels compared to the control group. Otherwise, no significant differences were found for the pre or post-trial fish In the pre-trial measurements, DA and 5 -HT levels were uniform across groups. T 13 fish had non-significantly elevated NE levels compared to control and L-Dopa levels differed non-significantly among treatments. However, the variation in L-Dopa did not appear to correspond to $\mathrm{Hg}$ body 
burden. With the exception of 5-HT, all neurotransmitter levels were similar in the posttrial groups.

Table 5. Muscle tissue $\mathrm{Hg}$ body burden (Mean \pm SE) and acetylcholine esterase activity (mean $\pm \mathrm{SE}$ ) after a 10 day waterborne exposure to $\mathrm{HgCL}$ immediately after exposure (pre-trial) and after a ten day behavioral trial during which time the fish were held in clean water (post-trial).

\begin{tabular}{lcc}
$\begin{array}{l}\text { Exposure } \\
\text { Conc } \\
(\mu \mathrm{g} / \mathrm{g})\end{array}$ & Muscle tissue & $\begin{array}{c}\text { AChE activity } \\
\text { (as \% of control })\end{array}$ \\
\hline $\begin{array}{l}\text { Pre-trial } \\
\text { Control }\end{array}$ & $0.10 \pm 0.02$ & $100.00 \pm 0.44$ \\
1.69 & $0.59 \pm 0.06$ & $125.23 \pm 0.54$ \\
6.79 & $4.40 \pm 0.61$ & $93.820 \pm 0.59$ \\
13.57 & $8.02 \pm 0.33$ & $109.46 \pm 0.67$ \\
\hline & & \\
\hline Post-trial & & $100.00 \pm 0.36$ \\
Control & $0.01 \pm 0.01$ & $101.02 \pm 0.32$ \\
1.69 & $0.59 \pm 0.06$ & $102.96 \pm 0.36$ \\
6.79 & $3.15 \pm 0.27$ & $100.07 \pm 0.29$ \\
13.57 & $7.27 \pm 0.63$ &
\end{tabular}


Table 6. Neurotransmitter levels (mean \pm SE) immediately after a 10-day waterborne exposure to $\mathrm{HgCl}$ (pre-trial) and after a 10-day trial period in which exposed fish were held in clean water (post-trial). An $\left(^{*}\right)$ indicates a significant difference with control

Conc

ng/mg Treatment conc $(\mu \mathrm{g} / \mathrm{L})$

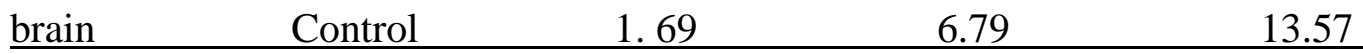

Pre trial

NE $\quad 0.416 \pm 0.065 \quad 0.374 \pm 0.054 \quad 0.403 \pm 0.042 \quad 0.513 \pm 0.062$

$\begin{array}{lllll}\text { L-dopa } & 0.227 \pm 0.059 & 0.365 \pm 0.098 & 0.186 \pm 0.049 & 0.276 \pm 0.104\end{array}$

DA $\quad 0.068 \pm 0.011 \quad 0.080 \pm 0.015 \quad 0.071 \pm 0.011 \quad 0.075 \pm 0.008$

\begin{tabular}{lllll}
$5-\mathrm{HT}$ & $0.104 \pm 0.021$ & $0.085 \pm 0.015$ & $0.110 \pm 0.020$ & $0.122 \pm 0.015$ \\
\hline
\end{tabular}

\section{Post trial}

NE $\quad 0.571 \pm 0.047 \quad 0.565 \pm 0.050 \quad 0.549 \pm 0.031 \quad 0.537 \pm 0.036$

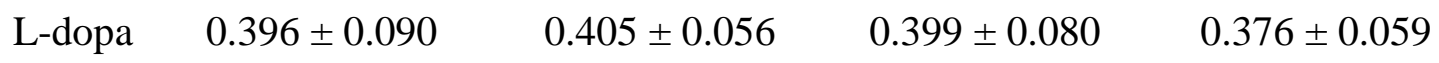

$\begin{array}{lllll}\text { DA } & 0.107 \pm 0.011 & 0.091 \pm 0.010 & 0.088 \pm 0.008 & 0.097 \pm 0.016\end{array}$

$\begin{array}{lllll}\text { 5-HT } & 0.155 \pm 0.015 & 0.119 \pm 0.009 & 0.119 \pm 0.010 & 0.117 \pm 0.008^{*}\end{array}$

Experiment Two. Pre-foraging trial appetite data revealed no significant differences among treatments (Table 7). Even though T13 fish ate fewer worms than the other groups the differences were not related to dose.

For the foraging trials, in order to minimize satiation and patch depletion, only data from the first two minutes of the 10 minute trial was used. Three learning metrics were used, 1.) percent time spent in the high food patch, 2.) percent of fish choosing to enter the high food patch first 3.) number of entries into the low food patch. Treatment means for the learning metrics were calculated using an average of the first two and an average of the last two days of the trial period. As noted above, fish fed in groups of three (5 groups/ treatment). 
Table 7. Average number of worms eaten per day (mean $+\mathrm{SE})$ during 10-day exposure to $\mathrm{HgCl}$. Each value represents the total treatment average of the average number of worms consumed/day by an individual fish. For statistical analysis data were square root transformed to achieve equal variance.

\begin{tabular}{lc}
$\begin{array}{l}\text { Exposure } \\
\text { Conc } \\
(\mu \mathrm{g} / \mathrm{L})\end{array}$ & $\begin{array}{c}\text { Worms consumed } \\
\text { (number/day) }\end{array}$ \\
\hline Control & $5.2 \pm 1.35$ \\
1.69 & $3.6 \pm 1.17$ \\
6.79 & $4.6 \pm 0.71$ \\
13.52 & $3.2 \pm 0.82$ \\
\hline
\end{tabular}

Comparisons of habitat use on the first and last two days revealed significant increases in the time spent in the high food patch for Controls and T 13 (two sample ttest $\mathrm{p}<.05$ for both) only (Table 8 ). However, on the last two days all groups spent more time in the high food patch (control, $\mathrm{p}<.0001 ; \mathrm{T} 1, \mathrm{p}<.001 ; \mathrm{T} 6, \mathrm{p}=.012 ; \mathrm{T} 13, \mathrm{p}=.0001$ ), and no treatment differences in habitat use were found.

Table 8. Percent of foraging time spent in the high food patch (mean of the first two and last two days) during the pre- switch feeding arrangement. $\quad(*)$ denotes a significant difference between the first and last two days within that treatment. All groups spent significantly more time in the high food patch on the last two days.

\begin{tabular}{lcc}
\multirow{2}{*}{$\begin{array}{l}\text { Exposure } \\
\text { conc }(\mu \mathrm{g} / \mathrm{L})\end{array}$} & \multicolumn{2}{c}{$\%$ time in high food patch } \\
\cline { 2 - 3 } Control & First two days & Last two days \\
1.69 & $46.4 \pm 11.5$ & $* 79.6 \pm 10.6$ \\
6.79 & $59.3 \pm 11.9$ & $73.6 \pm 8.2$ \\
13.57 & $61.5 \pm 16.5$ & $73.3 \pm 15.1$ \\
\hline
\end{tabular}

The first patch chosen was also similar for all treatments (Table 9). The mean percentage of fish choosing the high food patch first did increase over time, but on the end of the first 6 trial days there was still no significant tendency to choose the high food patch. No treatment effects on initial patch choice were found. 
Table 9. Mean ( $\pm 1 \mathrm{SE}$ ) percentage of first choices per day for the high food patch (mean of the first two and last two days) during the pre- switch feeding arrangement.

\begin{tabular}{llc}
$\begin{array}{lll}\text { Exposure } \\
\text { conc }(\mu \mathrm{g} / \mathrm{L})\end{array}$ & \multicolumn{2}{l}{$\%$ of first choices for high food patch } \\
\cline { 2 - 3 } Control & $38.3 \pm 7.26$ & Last two days \\
1.69 & $48.3 \pm 15.5$ & $66.7 \pm 10.5$ \\
6.79 & $70.0 \pm 8.6$ & $65.0 \pm 10.0$ \\
13.57 & $46.7 \pm 17.8$ & $48.3 \pm 8.1$ \\
\hline
\end{tabular}

The number of visits to the low food patch declined across trial days for controls and T1 only (two sample t-test, $\mathrm{p}<.05$ for both). However, on the last two days patch visitation was similar for all treatments (Table 10).

Table 10. Mean ( $\pm 1 \mathrm{SE}$ ) number of enters (mean of the first two and last two days) into the low food patch during the pre- switch feeding arrangement. (*) denotes a significant difference between the first and last two days within that treatment.

\begin{tabular}{lcc}
$\begin{array}{ll}\text { Exposure } \\
\text { conc }(\mu \mathrm{g} / \mathrm{L})\end{array}$ & First two days & Last two days \\
\hline Control & $1.35 \pm 0.43$ & $* 0.50 \pm 0.20$ \\
1.69 & $1.38 \pm 0.37$ & $* 0.62 \pm 0.21$ \\
6.79 & $0.61 \pm 0.26$ & $0.72 \pm 0.27$ \\
13.57 & $0.45 \pm 0.25$ & $0.37 \pm 0.29$ \\
\hline
\end{tabular}

After switching the relative food values of each patch, the fish showed greater preference for the new high food patch, but continued to spend more time on average in the low food patch. Consequently, preference for the high food patch was not statistically significant (Table 11) indicating a retention previously learned information. T 6 actually spent significantly more time in the low food patch $(\mathrm{p}<.005)$ on the last two days. 
Table 11. Percent of foraging time spent in the high food patch (mean of the first two and last two days) during the post- switch trial period.

\begin{tabular}{lcc} 
Exposure & \multicolumn{2}{l}{ \% time in high food patch } \\
\cline { 2 - 3 } conc $(\mu \mathrm{g} / \mathrm{L})$ & First two days & Last two days \\
\hline Control & $34.9 \pm 6.08$ & $52.7 \pm 16.0$ \\
1.69 & $39.0 \pm 8.04$ & $45.5 \pm 9.61$ \\
6.79 & $17.4 \pm 13.8$ & $25.5 \pm 4.40$ \\
13.57 & $30.2 \pm 11.9$ & $38.7 \pm 17.6$ \\
\hline
\end{tabular}

Following the switch, the control group had the highest, but non-significant, percentage of correct choices, followed by $\mathrm{T} 1$ fish (Table 12). No treatment chose the high food patch more than $50 \%$ of the time indicating the new low food patch continued to be sampled first, another indication that information from the pre-switch period was retained.

Table 12. Mean ( $\pm 1 \mathrm{SE}$ ) percentage of first choices per day for the high food patch (mean of the first two and last two days) during the post- switch trial period).

Exposure $\quad \%$ of first choices for high food patch

\begin{tabular}{lcl} 
conc $(\mu \mathrm{g} / \mathrm{L})$ & First two days & Last two days \\
Control & $13.3 \pm 9.72$ & $40.0 \pm 18.7$ \\
1.69 & $29.0 \pm 10.1$ & $56.7 \pm 11.3$ \\
6.79 & $13.3 \pm 9.72$ & $36.7 \pm 16.8$ \\
13.57 & $28.3 \pm 11.7$ & $25.3 \pm 19.4$ \\
\hline
\end{tabular}

Similarly all groups continued to make entries into what had been the high food patch (Table 13), however, over the post switch period, control fish showed a significant decline in visitation to the low food patch (two sample t-test, $\mathrm{p}<.05$ ). 
Table 13. Mean ( $\pm 1 \mathrm{SE})$ number of enters $\left(1^{\text {st }}\right.$ two minutes of trial) into the low food patch (mean of the first two and last two days) during the post- switch trial period). (*) denotes a significant difference between the first and last two days within that treatment.

\begin{tabular}{lcr}
$\begin{array}{l}\text { Exposure } \\
\text { conc }(\mu \mathrm{g} / \mathrm{L})\end{array}$ & Number of enters & Last two days \\
\cline { 2 - 3 } Control & $1.85 \pm 0.45$ & $* 0.90 \pm 0.34$ \\
1.69 & $1.23 \pm 0.28$ & $0.73 \pm 0.10$ \\
6.79 & $1.72 \pm 0.26$ & $1.76 \pm 0.27$ \\
13.57 & $1.45 \pm 0.23$ & $0.98 \pm 0.26$ \\
\hline
\end{tabular}

Biochemical analysis for experiment. 2. As in experiment one, no significant treatment differences in AChE activity were observed (Table 14).

Table 14. Muscle tissue Hg body burden (Mean \pm SE) and acetylcholine esterase activity (Mean $\pm \mathrm{SE}$ ) after a 10 day waterborne exposure to $\mathrm{HgCL}$ followed by a 10 day behavioral trial during which time the fish were held in clean water (post-trial).

Exposure Conc Muscle tissue

$(\mu \mathrm{g} / \mathrm{g})$ AChE activity

\begin{tabular}{llc} 
& $\mathrm{Hg}(\mu \mathrm{g} / \mathrm{g})$ & (as \% of control) \\
\hline Control & $0.012 \pm 0.005$ & $100.00 \pm 0.055$ \\
1.69 & $0.795 \pm 0.124$ & $109.95 \pm 0.037$ \\
6.79 & $2.949 \pm 0.213$ & $99.04 \pm 0.040$ \\
13.57 & $5.840 \pm 0.357$ & $97.43 \pm 0.034$ \\
\hline
\end{tabular}

As for neurotransmitters, L-Dopa was higher in the brain of control fish and significantly so compared to $\mathrm{T} 1$ (Table 15). No other significant differences were found for NE, DA, and 5-HT. Biochemical results of experiment one and two did not evince similar patterns among treatments, suggesting variations in biochemical endpoints did not seem to be related to $\mathrm{Hg}$ exposure. 
Table 15. Neurotransmitter levels (mean + SE) after a 10 day waterborne exposure to $\mathrm{HgCl}$ followed by a 10 day trial period in which exposed fish were held in clean water. The $6.79 \mu \mathrm{g} / \mathrm{L}$ treatment was not included in the statistical analysis due to the loss of several samples. An $(*)$ indicates a significant difference with control $(\mathrm{p}<.05)$

Conc

(ng/mg)

(brain) Treatment $(\mu \mathrm{g} / \mathrm{L})$

\begin{tabular}{lcccc} 
& Control & 1.69 & 6.79 & 13.57 \\
\hline NE & $0.464 \pm 0.051$ & $0.546 \pm 0.039$ & $0.535 \pm 0.072$ & $0.457 \pm 0.055$ \\
L-DOPA & $0.252 \pm 0.048$ & $0.113 \pm 0.030^{*}$ & $0.110 \pm 0.027$ & $0.155 \pm 0.030$ \\
DA & $0.089 \pm 0.019$ & $0.063 \pm 0.007$ & $0.070 \pm 0.014$ & $0.082 \pm 0.013$ \\
5-HT & $0.049 \pm 0.008$ & $0.054 \pm 0.006$ & $0.047 \pm 0.009$ & $0.056 \pm 0.007$ \\
\hline
\end{tabular}




\section{Chapter Four: DISCUSSION}

The first section of the discussion will attempt to explain the results of experiments one and two by mechanistic analysis of foraging behavior. Second, biochemical results will be interpreted and compared to related literature. Finally, the results of my experiment will then be examined with regard to their implications for aquatic systems in nature.

Experiment One. It was hypothesized that the foraging variables used in experiment one experiment would to be detrimentally altered by $\mathrm{Hg}$ exposure. In fact, several foraging variables were related to $\mathrm{Hg}$ body burden. As hypothesized, when compared on individual trial days, control fish captured more worms and in less time though only comparisons with T 6 and T 13 fish yielded significant differences. The results most often follow a dose response pattern in which body burden is inversely related to test performance. Also, using the best performance of individual fish, controls had significantly better mean performances when compared to the $\mathrm{T} 13$ group. The hypothesis that exposed fish would exhibit no improvement over trial days was confirmed in the case T 13 and in some instances T 6. Finally, it should be noted that all foraging trials took place while the fish were held in non-contaminated water suggesting persistent effects after exposure.

Among the factors related to foraging discussed in Fig 2 and 3, several could be possible explanations for the foraging deficits found in this study, including: 1.) Appetite suppression in exposed fish decreased the motivation to feed, 2.) Greater pause time exhibited by exposed fish, 3.) Sensory impairment and 4.) Treatment differences in learning to feed efficiently. Each will be discussed below.

Appetite suppression. As noted in the results, appetite suppression was not statistically evident in the pre- or post-trial tests. Other related endpoints were examined 
as well. Of interest was the time spent in the feeding area during the foraging trials. Those fish that spent all or most of their time in their compartment rather than the feeding area could be experiencing appetite suppression. Another possible indication of appetite suppression was rejection of prey items upon encounter. During the trials, prey rejection took the form of biting but not ingesting prey or spitting out prey after ingestion. Once again, no relationship between $\mathrm{Hg}$ and these two appetite responses was found (Table 16). Prey rejection was not found to differ significantly among treatments. Controls averaged more time in the feeding area compared to T 13 fish, but the difference was not significant, nor was the relationship between treatment and time spent dose response.

Table 16. Average time (mean $\pm \mathrm{SE}$ ) spent in feeding area and average number of prey rejections per encounter during the five minute behavioral trials. Each value represents the treatment average of the average time spent/ day by an individual fish. Time spent data were tested using a Kruskal-Wallis non-parametric procedure.

Exposure

Conc $(\mu \mathrm{g} / \mathrm{L})$ Avg time (sec/day) Number of rejections/encounter

Control

$$
240.5 \pm 6.67
$$

$0.14 \pm 0.028$

1.69

$246.4 \pm 12.7$

$0.11 \pm 0.023$

6.79

$251.0 \pm 8.47$

$0.16 \pm 0.031$

13.57

$224.1 \pm 11.4$ $0.17 \pm 0.033$

The interaction of $\mathrm{Hg}$ and appetite is not well studied. McKim (1976) using waterborne methylmercuric chloride (.29 $\mu \mathrm{g} / \mathrm{L} ; 273$ days) observed no appetite effects in trout with a muscle level of $3 \mu \mathrm{g} / \mathrm{g}$. Scherer et al., (1975) reported appetite suppression in walleye with muscle tissue concentrations of 5-8 $\mu \mathrm{g} / \mathrm{g}$. However, the walleye were fed fish containing methymercury $(\mathrm{MeHg})$ for 42 to 63 days. The exposure route and duration and the far greater toxicity of that $\mathrm{Hg}$ species, make a comparison between these two studies and mine difficult.

Differences in pause time. Pause time (lack of directional movement) differed among treatments (Table 3) indicating potential sensory/ CNS changes. Moreover, prey search behavior, of which pause time is an important component, is likely to affect 
encounter rates. Accordingly, the 7-day average time to three and four captures was regressed against the respective 7-day average pause time during those time intervals (Fig. 14 and 15). A significant inverse relationship between pause time and capture time was found for time to three and four encounters ( $p<.0001$ for both). Furthermore, treatment comparisons revealed significant differences in the pause time until three encounters (control vs T 13, p=.015) and four encounters (control vs. T13, p< .01) indicating pause time contributed to treatment differences in foraging success (Fig. 16).

Differences in pause time could result from nervous system depression (lethargy), greater handling time, failure to learn the most efficient search strategy, or general "mental confusion" (the last being very difficult to test). After reviewing the daily trials, no relationship between pause time and trial day was found, suggesting pause behavior was not a learned response to the habitat. Therefore, it seems that lethargy and handling time are the most likely influences on pause behavior. Though pollutants commonly affect both (Atchison et al., 1996), very few studies have used $\mathrm{Hg}$ as the toxicant. McKim et al., (1976) reported sluggishness in trout with body burdens of 5-7 $\mu \mathrm{g} / \mathrm{g}$, but not in those with $3 \mu \mathrm{g} / \mathrm{g}$. The duration of exposure may play a role as well. For example, during a 336 day exposure in $.247 \mu \mathrm{g} / \mathrm{L}$ methylmercury, Olson et al., (1975) observed no lethargy in fathead minnows though they had up to $11 \mu \mathrm{g} / \mathrm{g} \mathrm{Hg}$ in muscle tissue. My experiment used comparatively higher dose and lower duration and produced similar body burden and lethargy. The comparison suggests that, differences in exposure may produce similar body levels, but differ in affecting behavioral changes.

Also, handling time is often characterized by a period of stillness before prey search is resumed. In this way any treatment differences in handling time may partially account for treatment differences in pause time. To investigate further, pauses related to handling time were examined separately. In my study handling time was defined as the time from consumption to the resumption of a swimming search. Differences in average handling time and handling time per capture were present but none were significant (Table 17). Therefore, it is unclear whether handling time was relevant here. 
Table 17. Average handling time and handling time per capture (Mean $\pm \mathrm{SE})$.

\begin{tabular}{lcc}
$\begin{array}{l}\text { Exposure } \\
\text { Conc }(\mu \mathrm{g} / \mathrm{L})\end{array}$ & $\begin{array}{c}\text { handling time/ } \\
\text { capture }(\mathrm{sec})\end{array}$ & $\begin{array}{c}\text { average handling } \\
\text { time }(\mathrm{sec})\end{array}$ \\
\hline Control & $6.41 \pm 1.30$ & $10.83 \pm 1.63$ \\
1.69 & $7.39 \pm 1.32$ & $12.40 \pm 1.74$ \\
6.79 & $9.36 \pm 1.57$ & $14.41 \pm 1.47$ \\
13.57 & $10.23 \pm 1.19$ & $15.46 \pm 1.37$
\end{tabular}

Sensory impairment. I could find no comparable studies with which to establish a link between $\mathrm{Hg}$ and handling time. If such a link exists, it would probably involve gustatory impairment. In vitro studies have revealed that $\mathrm{HgCl}_{2}$ irreversibly binds to Lalanine receptors resulting in inhibition of taste receptor activity (Zelson and Cagan, 1979). General cell damage to taste organs is also associated with Hg exposure (Baatrup, 1991).

Visual impairment could also explain some performance deficits. Studies in fish are few but high doses of $\mathrm{Hg}$ were associated with exopthalmia and blindness in fish (Panigrahi and Misra, 1978) and lessened spectral discrimination (Hawryshyn, et al., 1978). In several other test organisms, $\mathrm{Hg}$ is detrimental to vision as well (WHO, 1980; Chang, 1979), but whether visual impairment was a factor in this experiment is unclear. More work needs to be done in understanding mercury's effect on vision.

Treatment differences in learning. In experiment one, the fish were introduced to a novel habitat and so a number of learning tasks were required if they were to forage successfully. For example, the fish had to learn that prey were buried. Second, they had to make the visual and locomotory accommodations necessary for a vegetated environment. Also, prey items were placed in the same locations every day, making retention of prey location information potentially important to foraging success. However, during the trials, individual fish did not seem to develop a specific search pattern, as neither movement within the aquarium nor the spatial sequence of captures 
was similar over days. This would suggest a random within-patch search pattern in which prey location information was not retained by the fish. Similar results were found by Marschall et al., (1989) and DeVries et al., (1989) using bluegill sunfish.

Experiment Two. The second experiment was designed to focus specifically on learning and it was hypothesized that compared to controls: 1.) exposed fish would show no discrimination between high food patch while foraging 2.) over trial days the exposed fish would exhibit no increase in their tendency to initially choose the high food patch 3.) treatment fish would show no decline in visitation to the low food patch and 4.) hypotheses $1-4$ would also be true upon a change in habitat characteristics. None of these hypotheses was confirmed, as the results showed no impairment of learning or retention due to $\mathrm{Hg}$ exposure. In the pre-switch period, all groups spent more time in the high food patch, and exhibited the same first patch choice and patch visitation behavior. After switching the relative food values of each patch, all groups continued to enter the former high food patch first and to spend comparatively more time (though less than during the pre-switch period) there.

These data suggest that all groups retained habitat information and, interestingly, no group made dramatic changes in habitat usage despite the habitat change. This is not surprising, as many investigators report that fish frequently depart from mathematical optimality models of habitat use and patch switching behavior (Pyke, 1984). Such a departure may be even more likely for experiment two in that there was low energy cost (short travel distance) associated with movement between patches.

Despite the results of my experiments, $\mathrm{Hg}$ may disrupt the process of memory consolidation. One mechanism could be the inhibition of ACh release from neurons. $\mathrm{Hg}$ acts at the neuromuscular junction and the synaptic cleft producing a weakened postsynaptic potentiation. Mercury, by altering ACh release, may impair memory formation because short and long term learning is facilitated by the induction of cellular changes that increase ACh release from the pre-synaptic terminals of neuronal circuits (Becker 
and Stevens, 1990). Another possible mechanism is the destruction of granule cells in the hippocampus, a primary center for learning and memory in higher vertebrates.

Comparing my results to past studies is difficult because, despite the existence of toxicological learning studies, very few used $\mathrm{Hg}$ as a toxicant. Those that did used conditioned response tests in which fish were trained to associate a light and a shock. After successful training, the treatment fish were exposed to $\mathrm{Hg}$ and retested. These studies reported impaired retention at waterborne exposures of $3 \mu \mathrm{g} / \mathrm{L}$ and $6 \mu \mathrm{g} / \mathrm{L} \mathrm{HgCL} 2$ using goldfish (Weir and Hine, 1970), and at body levels greater than $2.85 \mu \mathrm{g} / \mathrm{g}$ using rainbow trout (Hartman, 1978). In an operant conditioning test (target strikes with food as reinforcement) involving goldfish, Salzinger (1973) reported impaired retention at 6 and $10 \mu \mathrm{g} / \mathrm{L} \mathrm{HgCl}_{2}$. However, rainbow trout given a 4.6 or $6.2 \mu \mathrm{g} / \mathrm{g} \mathrm{MeHg}$ injection did not exhibit any learning deficits (Hawryshyn et al., 1982). In addition to fish, $\mathrm{Hg}$ is detrimental to memory in a variety of mammals including rats, humans (WHO, 1976) and in one study it inhibited learning and retention in grass shrimp (Barthalmus, 1977).

Lead, which has toxicity mechanisms similar to $\mathrm{Hg}$, affects memory in a variety of vertebrates. In an interesting study (Weber, 1991), fathead minnows underwent a four week lead exposure during which time they were allowed to feed on two size classes of daphnids. At the outset, all treatment fish initially consumed the largest prey size class after the start of the feeding trial, but in contrast to control fish the $.5 \mathrm{mg} / \mathrm{L}$ lead treatments took longer to switch to the smaller, easier to capture size class, while the $1 \mathrm{mg} / \mathrm{L}$ treatment never showed preference for the smaller prey at all. In explaining the results, the author cites impaired retention as potentially preventing the fish from learning from previous foraging bouts.

The results of the studies just mentioned would suggest that $\mathrm{Hg}$ could disrupt learning and retention at very low doses, though drawing firm conclusions is difficult due to the small number of studies and their methodological differences. For the same reasons, comparisons with my study present difficulties because the learning tasks in this experiment are unlike any found in the literature. 
Still, there are some possible explanations for the apparent lack of effect in my study. First, previous conditioning studies tested fish during the exposure period, whereas in my study the trials took place while fish were in clean water, in other words, during a recovery period. So, despite the fact that little $\mathrm{Hg}$ was depurated during the trial, after the initial exposure, the fish were not subject to continued dosing. $\mathrm{Hg}$ species may have been important as well. Compared to $\mathrm{HgCl}_{2}$, methylmercury (MeHg) passes the blood brain barrier more readily (Cavenaugh, 1977; Chang, 1979), making it more neurotoxic, though it should be noted that many older learning studies did use $\mathrm{HgCl}_{2}$.

Another explanation may be that learning trials in experiment two were not difficult enough to differentiate any treatment effects. However, the associative learning tests mentioned above are very simple as well, yet detection of learning deficits was possible. Regardless of whether $\mathrm{Hg}$ harms memory, in the future, ecologically relevant tests of learning and decision making will be of the most value.

\section{Biochemical Data}

Acetylcholinesterase Disturbing a process as central as AChE function could result in widespread effects on the central and peripheral nervous system including sensory, motor and autonomic function. Some studies (discussed below) with fish do suggest $\mathrm{Hg}$ alters AChE function. The proximate cause could be a conformational change brought about by the binding of $\mathrm{Hg}$ to a sulfhydryl group on the cholinesterase. Another means could be the destruction of anticholinergic cells. Whatever the mechanism, the result would be an accumulation of acetylcholine ( $\mathrm{ACh}$ ) in nerve synapses and, therefore, a prolonged depolarization (Weber, 1994). This would cause higher nerve sensitivity and hyperactivity/ spastic muscle movements.

Interestingly, in my experiment, AChE activity in fish tested immediately after exposure and after the trials exhibited no treatment effect. Though the results presented here were incongruous with the literature, older studies used greater exposure levels. For example, in experiments with carp (Cyprinus carpio), brain and muscle AChE both

declined after $\mathrm{HgCl}_{2}$ exposure (Sastry and Sharma, 1980; Suresh et al., 1992), but the 
exposure concentrations were between 100 and $300 \mathrm{ug} / \mathrm{L} \mathrm{HgCl}_{2}$. Despite the fact that these exposure levels lacked environmental realism, the results may be telling. Using field collected fish, Shaw and Panigrahi (1990) found a strong negative correlation between brain mercury level and AChE activity, indicating a potential field validation of lab findings. The fact that AChE activity was not altered in this study may be related to not only the low dose but also the acclimation ability of the fish. In the laboratory studies just mentioned, there is an initial decline followed by an increase in AChE activity with time (sometimes to control level). This acclimation, likely due to glutathione and metallothionine induction, could moderate the toxicity. In short, it seems $\mathrm{Hg}$ may alter $\mathrm{AChE}$ function but in the present study the low exposure and ten day duration may have allowed the fish time to acclimate.

Brain neurotransmitters Though the function of neurotransmitters in fish is not well understood, neurotransmitters do influence a variety of foraging behaviors and learning processes (Smith, 1984). In published studies, though they are few, both MeHg and $\mathrm{HgCl}_{2}$ altered monoamine levels in brain tissue. After day 90 of a 180 day exposure, Kirubagaran and Joy (1990) reported a time related decline in 5-HT and monoamine oxidase (MAO) along with a rise in NE and DA. However, no changes were reported on day 45 (the first sampling period). Also, the catfish (Clarisas batrachus) used in the study were exposed to either $50 \mathrm{ug} / \mathrm{L} \mathrm{HgCl}_{2}$ or $40 \mathrm{ug} / \mathrm{L} \mathrm{MeHgCl}$, far greater levels than those used in the present experiment. Zhou, et al., (1999) using larval killifish (Fundulus heteroclitus) from a $\mathrm{Hg}$ polluted and non polluted sites noted higher DA concentrations in the former but no differences in 5-HT. Zhou also exposed both fish from both populations to $10 \mathrm{ug} / \mathrm{L} \mathrm{MeHg}$. For fish from the reference site, there was an increase in 5-HT and DA (likely caused by a reduction in their metabolism) while fish from the polluted site exhibited fluctuating levels of both neurotransmitters. Lead exposure, very similar to $\mathrm{Hg}$ in its etiology, has also been found to increase 5-HT and NE in the brain of fathead minnows (Weber, 1991). Clearly, more work is needed to elucidate the interaction of $\mathrm{Hg}$ and neurotransmitters

In my study and the experiments just mentioned used whole brain and therefore 
were incapable of distinguishing local changes in neurotransmitter levels. This is crucial, as production and metabolism of neurotransmitters vary by brain region in fish (Hornby and Piekut, 1990) just as they do in other animals. In fact, Hg toxicity in the brain does seem to be spatially dependent. Using killifish from polluted and unpolluted sites the medulla, but not cerebellum, levels of 5-HT were found to be lower in specimens from the $\mathrm{Hg}$ contaminated water. In the same fish, DA levels did not differ in the cerebellum or the medulla (Smith et al., 1993). In another study, tilapia (Oreochromis mossambicus) were exposed to 15 and $30 \mathrm{ug} / \mathrm{L} \mathrm{HgCl}_{2}$ for 6 months (from 7day post hatch on) and then 5-HT concentrations were measured in the hypothalamus, telencephalon, and optic lobe. All groups showed anatomical and sex specific variation, and significant differences related to $\mathrm{Hg}$ were only found for the hypothalamus of males (Tsai et al., 1995). The importance of brain region in $\mathrm{Hg}$ toxicity has also been noted for mammals (Lakshama et al., 1993). Considering prior research, the lack of effect in my study may have resulted from low exposure level and duration and, due to the small size, the inability to examine the fish brain by specific anatomical region. Consequently, any local differences were too small to be resolved.

Finally, though not tested here, $\mathrm{Hg}$ can impact brain function by other means such as altering metabolic enzymes like glucose-6-phosphate, succinic dehydrogenase, and pyruvate and lactate dehydrogenase (Sastry and Sharma, 1980; Sastry and Rao, 1981). The activity of ATP dependent ion pumps $\left(\mathrm{Ca}^{++}, \mathrm{Na}^{+}, \mathrm{Mg}^{++}\right.$, and $\left.\mathrm{NA}^{+} / \mathrm{K}^{+}\right)$can decline upon exposure to $\mathrm{Hg}$ as well (Verma et al., 1983; Ravichandra, et al., 1988). Biochemically, $\mathrm{Hg}$ acts at the neuromuscular junction and synaptic cleft producing a weakened post- synaptic potentiation. This well studied mechanism involves inhibition of calcium by $\mathrm{Hg}$ at sites on the $\mathrm{Ca}^{++}$channels of the presynaptic terminal. The result is a decrease in $\mathrm{Ca}^{++}$uptake and a concomitant decrease in ACh release into the synaptic cleft or neuromuscular junction (Cooper et al., 1984). Because the release of other neurotransmitters is also dependent on $\mathrm{Ca}^{++}$uptake, $\mathrm{Hg}$ may alter their activity as well. The potential this creates for disrupting learning was mentioned above. More studies on interaction of mercury and neurotransmitters is needed. 


\section{$\underline{\text { Environmental Relevance }}$}

In understanding the significance of the results reported here it is important to consider tissue levels, as the waterborne exposure was greater than that typically found in nature. Aside from samples taken at a point source, water column $\mathrm{Hg}$ concentrations rarely exceed 10 to $40 \mathrm{ng} / \mathrm{l}$ in polluted lotic and lentic systems (Wiener and Spry, 1996). The situation is much different with sediments, where trapped $\mathrm{Hg}$ can be 1000 times greater than water column levels. An example from Virginia is the South River in which sediments contained up to $60 \mathrm{ppm}$ as far as 40 river miles from the $\mathrm{Hg}$ discharge site (Messing, 1998). Therefore, in natural systems, waterborne exposure would likely be intermittent, occurring particularly after storms. This sediment flux is important to mercury dynamics, because it is in anaerobic sediments that $\mathrm{Hg}$ is converted to $\mathrm{MeHg}$, the form most readily taken up by organisms (Jensen and Jernelov, 1972).

In my study, $\mathrm{Hg}$ body burden increased with exposure dose (Table 5 and 11). Muscle samples contained less than 1 ppm (for T1) to over 8 ppm (in the pre-trial T13 group). Control fish had between .1 and $.012 \mathrm{ppm}$, levels typical in fish collected from non-polluted environments lacking conditions which promote metal bioavailability, i.e. low pH and warm temperature (Wiener and Spry, 1996; Rose, et al., 1999). In aquatic systems that have natural mercury deposits or conditions favorable to availability, levels similar to those found in T1 would not be uncommon. In polluted areas, piscivorous or bottom feeding fish can contain mean tissue concentrations from 1 to $7 \mathrm{ppm}$ depending on factors like age and distance from point source. These values are equivalent to those reported for T6 and, though on the high end, T 13.

In gauging environmental relevance, there are two other considerations: fish and mercuric species. Mercury accumulation is partially a function of longevity, and to a lesser degree trophic level, which is why larger piscivorous species often have the highest levels (Hildebrand et al., 1980; Ward and Neumann, 1999). Therefore, short lived species like the fathead minnow would rarely accumulate levels above $1 \mathrm{ppm}$ in natural systems. However, it is important to note that most (90-95\%) of the total mercury found in field collected specimens is the most toxic form of mercury: $\mathrm{MeHg}$ rather than the 
inorganic form used here (Bloom, 1992; AMRL, 1998). Also, for the fathead minnow and species occupying similar trophic levels, benthic detritus often constitutes a significant dietary component. By feeding in substrates, the fathead minnow would potentially increase $\mathrm{Hg}$ uptake via gill or dietary routes. Finally, fish were tested during a recovery period in which body stores were the only source of exposure. So, despite the uncertainty inherent in any extrapolation from lab to field, the results reported in this study have potential implications for fish in nature.

If fish are unable to acquire food efficiently, the life history, reproductive and, potentially, ecological implications are profound. For example, in my study $\mathrm{Hg}$ was found to decrease foraging efficiency, a component of bioenergetics models. General energy budgets such as the following:

$$
\text { Consumption }=\text { Growth }+ \text { Egestion }+ \text { Ingestion }+ \text { Metabolism }+ \text { Work }
$$

illustrate the direct relationship between growth and food consumption. The Consumption and Work variables can be broken down into a variety of components, among them, the foraging ability variables used in this study. For example, decreased foraging efficiency could mean that for a given time period more energy is expended searching (increase in search time), while actual food consumption over that time period is reduced.

Bioenergetics based behavioral toxicology offers several possibilities for ecotoxicologists. For example, mathematical models of net energy gains from foraging could be tested using toxicant exposed fish. These models could then be used to predict pollution induced alterations in growth, reproduction, and metabolism in the wild. Other mathematical models related to foraging behavior could also be examined, such as models of prey choice (e.g. Optimal foraging theory) and habitat preference (e.g. ideal free distribution, patch departure modeling).

The traditionally toxicologists approach pollution stress from a clinical reference 
point that emphasizes lethal dosages and cellular and molecular mechanisms of toxicity. Such studies require a controlled environment and as a result traditional studies are laboratory based. One major drawback to this approach is that environmental relevance is often not clearly defined. No attempt is made to relate alterations at the cellular/ molecular level to higher levels of ecosystem organization (e.g. individual or community). In addition, many toxicity tests rely on environmentally unrealistic, high dose, short duration exposures, which makes any laboratory- field validation much more difficult. The result often seems to be toxicity testing for its own sake, rather than toxicity testing that can be used to address practical needs.

In contrast, toxicity tests that examine foraging behaviors focus one's attention on variables whose environmental relevance is easily recognized. In addition, behavioral studies in general are sensitive pollution indicators. As such, the results of behavioral tests could are good candidates for use in formulating the Maximum Acceptable Toxicant Concentrations (MATC) used in determining regulatory statutes.

However, long-term adaptation to low to moderate levels of pollution is possible making behavioral studies with field collected fish necessary. One very promising approach (Weis and Weis, 1995; Smith and Wiess, 1997, Smith et al., 1995) is to perform laboratory comparisons of foraging ability using fish collected from polluted sites and reference sites. Studies using this method have consistently found greater predator susceptibility and decreased prey capture rates in fish collected from the polluted site. In addition, molecular aspects were addressed in studies attempting to correlate behavioral deficits with neurotransmitter levels. Field study provided some support for laboratory findings in that live prey accounted for $12 \%$ of the gut contents of fish sampled from the polluted site versus $60 \%$ in reference fish (Smith and Weiss, 1997). The difference could be the result of site specific differences in available food items, therefore further study is necessary.

Still, this approach, is a potentially powerful tool for accomplishing the purpose of ecotoxicology; namely investigating the effects of environmental pollution in an 
ecological context in order to understand the ways in which contaminants alter organizational levels and linkages within ecosystems. It is only with an ecosystem level understanding that we can regulate the discharge of pollutants with a full knowledge of their impacts. 
References

Applied Marine Research Lab, 1998. A comprehensive evaluation of the South River and South Fork Shenandoah River for mercury contamination: final report. AMRL technical Report No. 3079.

Atchison, G.J., M.B. Sandheinrich, and M.D. Bryan, 1996. Effects of environmental stressors on interspecific interactions of aquatic animals. IN: Exotoxicology: A Hierachical Treatment.

Baatrup, E., 1991. Structural and functional effects of heavy metals on the nervous system, including sense organs, of fish. Comparative Biochemistry and Physiology C 100 (1/2) 253-57.

Babcock, M.M., 1985. Morphology of olfactory epithelium pink salmon, Oncorhynchus gorbuscha, and changes following exposure to benzene: a scanning electron microscopy study. In: Marine Biology of Polar Regions and Effects of Stress on Marine Organisms, Gray, J. and Christensen, M. Eds. Proceedings of 18th EMBS, Oslo.

Barthalamus, G.T., 1977. Behavioral effect of mercury on grass shrimp. Marine Pollution Bulletin 8: 87-90.

Bekkers J.M. and C.F. Steven, 1990. Presynaptic mechanism for long-term potentiation in the hippocampus. Nature 346: 724-29.

Besch, QW.K., A. Kemball, K. Meyer-Waarden, and B. Scharf. 1977. A biological monitoring system employing rheotaxis of fish. Pages 56-74 in J. Cairnes, Jr., K.L. Dickson and G.F. Westlake, editors. Biological Monitoring of Water and Effluent Quality. American Society for Testing and Material, SP 607, Philadelphia.

Beitinger, T.L., 1990. Behaviroral reactions for the assessment of stress in fishes. Journal of 
Great Lakes Research, 16:595-528.

Bodamer, J., 1985. Corneal damage in larvae of striped bass, Morone saxatilis exposed to copper. Transactions of the American Fisheries Society, 114: 577.

Brown, J.A., P.H. Johansen, P.W. Colgan and R.A. Mathers, 1985. Changes in the predatoravoidance behavior of juvenile guppies (Poecilia reticulanta) exposed to pentachlorophenol. Canadian Journal of Zoology. 63: 2001-2005.

Brown, J.A., P.H. Johansen, P.W. Colgan and R.A. Mathers, 1987. Impairment of early feeding behavior of largemouth bass by pentachlorophenol exposure: a preliminary assessment. Transactions of the American Fisheries Society 116: 71-78.

Bryan, M.D., G.J. Atchison, and M.B. Sandheinrich, 1995. Effects of cadmium on the foraging behavior and growth juvenile bluegill (Lepomis macrochirus). Canadian Journal of Fisheries and Aquatic Science 52: 1630-1638.

Bloom, N.S., 1992. On the chemical form of mercury in edible fish and marine invertebrate tissue. Canadian Journal of Fisheries and Aquatic Science 49: 1010-1117.

Cavenagh, J.B., 1977. Metabolic mechanisms of neurotoxicity caused by mercury. Pgs 283288 In: Neurotoxicology, L.R. H. Shiraki and N. Grcevic eds. Raven Press, New York.

Chang, L.W., 1979. Pathological effects of mercury poisoning. Pgs 519-580 In: The Biogeochemistry of Mercury in the Environment, J.O. Nriagu ed. Elsevier/North-Holland Biomedical press, Amsterdam.

Cleveland, L., E.E. Little, S.J. Hamilton, D.R. Buckler and J.B. Hunn. 1986. Interactive toxicity of aluminum and acidity to early life stages of brook trout. Transactions of the American Fisheries Society. 115:610-620. 
Colgan, P.W., J.A. Brown, and S.D. Orsatti, 1986. Role of diet and experience in the development of feeding behavior in largemouth bass, Micropterus salmoides. Journal of Fish Biology 28: 161-170.

Cooper, G.P., J.B. Suszkiw and R.S. Manalis, 1984. Presynaptic effects of heavy metals. Pgs 121 In: Cellular and Molecular Neurotoxicology T. Narahashi ed. Raven Press, New York.

Croy, M. I. and Hughes, R. N, 1990. The role of learning and memory in the feeding behaviour of the fifteen-spined stickleback, Spinachia spinachia L. Animal Behavior 41: 149159.

DeVries, D.R., R.A. Stein and P.L. Chesson, 1989. Sunfish foraging among patches: the patch departure decision. Animal Behavior 37: 455-64.

Eggers, D.M., 1977. The nature of prey selection by planktivorous fish. Ecology 58: 46-56.

Ehlinger, J.T., 1989. Learning and individual variation in bluegill foraging: habitat-specific techniques. Animal Behavior 38: 643-658.

Ehlinger, T.J., 1990. Habitat choice and phenotype-limited feeding efficiency in bluegilll: individual differences and trophic polymorphism. Ecology 71: 886-896.

Ellgaard, E.G., J.E. Tusa and A.A. Malizia, 1978. Locomotor activity of the bluegill Lepomis macrochirus: hyperactivity induced by sublethal concentration of cadmium, chromium, and zinc. Journal of Fish Biology 1: 19.

Elman, G.L., D.Courtney, O. Andres and R. Featherstone, 1961. A new and rapid colorimetric determination of AChE activity. Biochemical Pharmocology 7: 88-95.

Farmer, G.J., D. Ashfield, and H.S. Samant, 1979. Effects of zinc on juvenile Atlantic salmon, 
Salmo salar: acute toxicity, food intake, growth and bioaccumulation. Environmental pollution 19: 103-117.

Finger, S.E., E.E. Little, M.G. Henry, J.F. Fairchild and T.P. Boyle, 1985. Comparison of laboratory and field assessment of fluorine. I. Effects of fluorine on the survival, growth reproduction and behavior of aquatic organisms in laboratory tests. In: Validation and Predictability of Laboratory Methods for Assessing the Fate and Effects OF Contaminants in Aquatic Ecosystems. ASTM STP 85, Edited by T.P. Boyle, American Society for Testing and Materials, Phliladelphia, PA, PP. 120-133.

Gardner, G.R. and C. LaRoche, 1973. Copper induced lesions in estuarine teleosts. Journal of the Fisheries Research Board of Canada 30: 363.

Goodyear, C.P., 1972. A simple technique for detecting effects of toxicants or other stresses on a predator-prey interaction. Transactions of the American Fisheries Society 101: 367-370

Gotceitas, V., 1990 (a). Foraging and predator avoidance: a test of a patch choice model with juvenile bluegill sunfish. Oecologia 83: 346-351.

Gotceitas, V., 1990 (b). Variation in plant stem density and its effects on foraging success of juvenile bluegill sunfish. Environmental Biology of Fishes 27: 63-70.

Gotceitas, V. and P. Colgan, 1990. The effects of prey availability and predation risk on habitat selection by juvenile bluegill sunfish. Copeia 409-417.

Hairston, N.G., Li, K.T., and S.S. Easter, 1983. Fish vision and the detection of planktonic prey. Science 218: 1240-42.

Hara, T.J., Y.M.C. Law and S. MacDonald, 1976. Effects of mercury and copper on the olfactory response in rainbow trout, Salmo gairdneri. Journal of the Fisheries Research Board of Canada 33: 1568. 
Hartman, A.M., 1978. Mercury feeding schedules: effects on accumulation, retention and behavior in trout. Transaction of the American Fisheries Society 107: 369-375.

Hatfield, C.T. and J.M. Anderson, 1972. Effects of two insecticides on vulnerability of Atlantic (Salmo salar) parr and brook trout (Salvelinus fontinalis) to predation. Journal of the Fisheries Research Board of Canada 29:27-29.

Hatfield, C.T. and P.H. Johansen, 1972. Effects of four insecticides on the ability of atlantic salmon parr (Salmo salar) to learn and retain a simple conditioned response. Journal of the Fisheries Research Board of Canada 29: 315-321.

Hawryshyn, C.W., W.C. Mackay and T.H. Nilsson, 1982. Methyl mercury induced visual deficits in rainbow trout. Canadian Journal of Zoology 60: 3127.

Heath, A.G. 1995. Water Polution and Fish Physiology, 2nd ed. CRC Press: Boca Raton, FL

Heath, A.G. J.J. Cech, J.G. Zinkl, R. Finlayson and R. Fujimura, 1993. Sublethal effects of methyl parathion, carbofuran and molinate on larval striped bass. American Fisheries Society Symposium 14: 17-28.

Heath, A.G. J.J. Cech Jr., L. Brink, P. Moberg and J. G. Zink1, 1997. Physiological respones of fathead minnow larvae to rice pesticides. Ecotoxicology and Environmental Safty37: 280-288.

Hedtke, J.I., and I.A. Norris, 1980. Effect of ammonium chloride on predatory consumption rates of brook trout (Salvelinus fontinalis) on juvenile chinook salmon (Oncorhynchus tshawytscha) in laboratory streams. Bulletin of Environmental Contamination and Toxicology 24: 81-89.

Hikada I., 1970. The effects of transition metals on the palatal chemoreceptors of the carp. 
Japanese Journal of Physiology.

Hildebrand, S.G., Strand, RH, and Huckabee, J.W., 1980. Mercury accumulation in fish and invertebrates of the North Fork Holston River Virginia and Tennessee. Journal of Environmental Quality 9: 393.

Holecombe, G.W., J.T. Fiandt and G.L. Phipps, 1980. Effects pH increases and sodium chloride addition on the acute toxicity of 2,4 , - dichlorophenol in the fathead minnow. Water Research 14: 1073-1077.

Huckabee, J.W. J.W. ELwoood and S.G. Hildebrand, 1979. Accumulation of mercury in freshwater biota. Pgs 277- 302 In: The Biogeochemistry of Mercury in the Environment, J.O. Nriagu ed. Elsevier/North-Holland Biomedical press, Amsterdam.

Hughes, R.N., M.J. Kaiser, P.A. Mackney and K. Warburton, 1992. Optimizing foraging behaviour through learning. Journal of Fish Biology 41 (Suppt. B), 77-91.

Janssen, J., 1982. Comparison of searching behavior for zooplankton in a n obligate planktivore, blueback herring (Alosa aestivalis) and a facultative planktivore, bluegill (Lepomis macrochirus). Canadian Journal of Fisheries and Aquatic Science 39:1649-1654.

Kania, H.J. and J. O'Hara. 1974. Behaviora alteration in a simple predator-prey system due to sublethal exposure to mercury. Transaction of the American Fisheries Society 103: 134136.

Kirubagaran, R., Joy, K.P. 1990. Changers in brain monoamine levels and monoamine oxidase activity in cafish (Clarias batrachus), during chronic treatment with mercurials. Bulletin of Environmental Contamination and Toxicology. 45: 88-93.

Koltes, K.H., 1985. Effects of sublethal copper concentrations on the structure and activity of Altantic silverside schools. Transactions of the American Fisheries Society. 114: 413. 
Lakshmana, M.K., Desiraju, T., Raju, T.R. 1993. Mercuric chloride-induced alterations of levels of noradrenaline, dopamine, serotonin and acetylcholine esterase activity in differenc regions of rat brain during postnatal development. Archives of Toxicology 67: $422-7$.

Little, E.E., R.D. Archeski, B.A. Flerov and V.I. Kozlovskaya, 1990. Biological indicators of sublethal toxicity in rainbow trout. Archives of Environmental Contamination and Toxicology.19: 380-385.

Little, E.E., J.F. Fairchild, and A.J. Delonay, 1993. Behavioral methods for assessing impacts of contaminants on early life stage fishes. American Fisheries Society Symposium 14: 6776.

Marschall, E.A., P.L. Chesson and R.A. Stein, 1989. Foraging in a patchy environment: preyencounter rat and residence time distributions. Animal Behavior 37: 444-454.

Mathers, R.A., J.A. Brown, and P.H. Johansen, 1985. The growth and feeding behavior responses of largemouth bass (Micropterus salmoides) exposed to PCP. Aquatic Toxicology 6: 157-164.

McKim, J.M., G.F. Olson, G.W. Holcombe and E.P. Hunt. 1976. Long term effects of methylmercuric chloride on three generation of brook trout (Salvelinus fontinalis): toxicity, accumulation, distribution and elimination. Journal of the Fisheries Research Board of Canada 33: 2726-39.

McNicholl, P.G., and W.C. Mackey, 1975. Effect of DDT on learning a simple conditionresponse in rainbow trout (Salmo gairdneri). Journal of the Fisheries Research Board of Canada. 32: 661-665.

Mehrle, P.M., D.R. Buckler, E.E. Little, L.M. Smith, J.D. Petty, P.H. Peterman, D.L. Stalling, 
G.M. DeGreaeve, J.J. Coyle, and W.J. Adams, 1988. Toxicity and bioconcentration2,3,7,8,-tetrachlorodibenzodioxin and tetrachlorodibenzofuran in rainbow trout. $\quad$ Environmental Toxicology and Chemistry 7: 47-62.

Mittlebach, G.G., 1981. Foraging efficiency and body size: a study of optimal diet and habitat use by bluegills. Ecology 62: 1370-1386.

Morgan, M.J. and J.G.J. Godin, (1985). Antipredator benefits of schooling behavior in a cyprinodaontid fish, the banded killifish (Fundulus diaphanus) Z. Tierpsychol. 70:236-246.

Neill, S.R.StJ. and J.M. Cullen, 1974. Experiments on whether schooling by their prey affects the hunting behavior of cephalopod and fish predators. Journal of Zoology, Lond,., 172: 549-569.

Nyman, H.G., 1981. Sublethal effects of lead $(\mathrm{Pb})$ on size selective predation by fishapplication on the ecosystem level. Ver. Internat. Verin. Limnol. 21: 1126-1130.

O’Brien, W.J., N.A. Slade and G.L. Vinyard, 1976. Apparent size as the determinant of prey selection by bluegill sunfish (Lepomis machrochirus). Ecology 57: 1304-1310.

O’ Brien, W.J., B.I. Evans and H.I. Browman, 1989. Flexible search tactics and efficient foraging in saltatory searching animals. Oecologia 80: 100-110.

Olson, G.F. D.I. Mount, V.M. Snarski and I.W. Thorslund, 1975. Mercury residues in fathead minnows, Pimephales promelas Rafinesque, chronically exposed to methylmercury in water. Bulletin of Environmental Contamination and Toxicology 14: 129-34.

Paszowski, C.A. and B.L. Olla, 1985. Foraging behavior of hatchery-produced coho salmon (Oncorhynchus Kisthuc) smolts on live prey. Canadian Journal of Fisheries and Aquatic Science 42:1915-21. 
Panigrahi, A.K., and B.N. Misra, 1978. Toxicological effects of mercury on freshwater fish, Anabas scandens Val. and their ecological implications. Environmental Pollution 16: 31

Pyke, G.H., 1984. Optimal foraging theory: a critical review. Annual Review of Ecology and Systematics 15: 523-75.

Ranta, E. and V. Nuutinen, 1986. Experience affects performance of ten-spined stickleback foraging on zooplankton. Hydrobiologia 140: 161-166.

Ravichandra, S.R., R.R Jinna, J.E. Uzodinma, and D. Desaiah. 1988. In vitro effect of mercury and cadmium on brain Ca ATPase of the catfish Ictalurus punctatus. Bullentin of Environmental Contamination and Toxicology 41:324-28.

Rose, J., M.S. Hutcheson, C.R. West, O. Pancorbo, K.Hulme, A. Cooperman, G. DeCesare, R. Isaac, A. Screpetis. 1999. Fish mercury distribution in Massachusetts, USA lakes. Environmental Toxicology and Chemistry 18: 1370-79.

Salzinger, K., S.P. Fairhurst, S.J. Friemark and F.D. Wolkoff, 1973. Behavior of the goldfish as an early warning system for the presence of pollutants in water. Journal of Environmental Systems 3:27-40.

Salzman, S.K., C.L. Llados Eckman, and E. Hirofuji. 1985. Determination of spinal cord monoamines and metabolites using three micron columns and dual electrochemical detection. Journal of Liquid Chromatography 8(2) 345-360.

Sandheinrich, M.B. and G.J. Atchison, 1989. Sublethal copper effects on bluegill, (Lepomis macrochirus), foraging behavior. Canadian Journal of Fisheries and Aquatic Science 46:1977-1985.

Sandheinrich, M.B. and G.J. Atchison, 1990. Sublethal toxicant effects on fish foraging behavior: empirical vs. mechanistic approaches. Environmental Toxicology and 
Chemistry 9: 107-119.

Sastry, K.V. and K. Sharma. 1980. Effects of mercuric chloride on the activities of brain enzymes on a fresh water teleosts, Ophiocephalus (Channa) punctatus. Archives of Environmental Contamination and Toxicology. 9: 425-430.

Sastry, K.V. and D.R. Rao. 1981. Enzymological and biochemical changes produced by mercuric chloride in a teleosts fish, Channa punctatus. Toxicology Letters 9: 321-26.

Scherer, E., P.A. Armstrong, and S.H. Nowak. 1975. Effects of mercury contaminated diet upon walleyes, Stizostedion vitreum vitreum (Mitchell). Canadian Fisheries and Marine Service Resources Division Branch Winnipeg Technical Report No. 597.

Scmittt, R.J. and S.J. Holbrook, 1985. Patch selection by juvenile black surfperch (Embiotocidae) under variable risk: interactive influence of food quality and structural complexity. Journal of Experimental Marine Biology and Ecology 85: 269-85.

Suresh, A., B. Sivaramakrishna, P.C. Victoriamma, K. Radhakrishnaiah. 1992. Comparative study on the inhibition of acetylcholinesterase activity in the freshwater fish Cyprinus carpio by mercury and Zinc. Biochemistry International 26: 367.

Smith, G.M. A.T. Khan, J.S. Weis and P.Weis, 1995. Behavior and brain chemistry correlates in mummichogs (Fundulus heteroclitus) from polluted and unpolluted environments. Marine Environmental Research 39: 329-333

Smith, G.M., and J.S. Weiss, 1997. Predator-prey relationships in mummichogs (Fundulus heteroclitus (L.)): effects of living in a polluted environment. Journal of Experimental Marine Biology and Ecology 209: 75-87.

Smith, J.R., 1984. Fish neurotoxicology, in Aquatic Toxicology, Vol 2, Weber, L.J., Ed., Raven Press, New York. 
Smith, L.L., Jr., D.M. Oseid, G.L. Kimball and S.M. El-Kandelgy, 1976. Toxicity of hydrogen sulfide to various life history stages of bluegill (Lepomis macrochirus). Transactions of the American Fisheries Society 105: 442-449.

Sutterlin, A.M. and N. Sutterlin, 1970. Taste responses in Atlantic salmon (Salmo salar) par. Journal of the Fisheries Research Board of Canada 27: 1927.

Stephens, D.W. and J.R. Krebs, 1986. Foraging Theory. Princeton University Press, Princeton, N.J.

Strickler-Shaw, S., and D.H. Taylor. 1991. Lead inhibits acquisition and retention learning in bullfrog tadpoles. Neurotoxicology and Teratology 13: 167-73.

Sun, T., and Taylor, D.H., 1983. The effects of parathion on acquisition and retention of shuttlebox avoidance-conditioning in the goldfish, Carassius auratu. Environmental Pollution (Series A) 31: 119-131.

Schwartz, J.H., L. Bernier, V.F. Castellucci, M. Palazzolo, T. Saitoh, A. Stapelton and E.R.. Kandel, 1983. What molecular steps determine the time course of the memory for shortterm sensitization in Aplysia? Cold Spring Harbor symposium. Quant. Biology. $\quad 48$ : 811-19.

Thomas, R.E. and S.D. Rice, 1987. Effect of water-soluble fraction of cook inlet crude oil on swimming performance and plasma cortisol in juvenile coho slamon (Oncorhynchus kisutch). Comparative Biochemistry and Physiology 87: 177.

Taylor, T.J. and V. DiStefano, 1976. Effects of methylmercury on brain biogenic amines in the developing rat pup Toxicology and Applied Pharmacology 38: 489-497.

Tsai, C., T. Jang, L. Wang., 1995. Effects ofmercury n serotonin concentration in the brain of 
tilapia, Oreochromis mossambicus. Neuroscience Letters 184: 208-11.

Turner, A.M. and G.G. Mittelbach, 1990. Predator avoidance and community structure: interactions among piscivores, planktivores and plankton. Ecology 71: 2241-2254.

Verma, R., M. Jain, and I.P. Tonk. 1983. In vivo effect of mercuric chloride on tissue ATPases of Notopterus notopterus. Toxicology Letters 16: 305-309.

Waiwood, K.G. and P.H. Johansen, 1978. The effect of copper, hardness and $\mathrm{pH}$ on the growth of rainbow trout, Salmo gairdneri. Journal of Fish Biology 13: 591.

Walton, W.E., N.G. Hairston, Jr. and J.K. Wetterer, 1992. Growth related constraints on diet selection by sunfish. Ecology 73: 429-437.

Warburton, K., 1990. The use of local landmarks by foraging goldfish. Animal Behavior 40: 500-505.

Ward, S.M. and R.M. Neumann. 1999. Seasonal variations in concentrations of mercury in axial muscle tissue of largemouth bass. North American Journal of Fisheries Management 19: 89-96.

Weber, D. N., A. Russo, D.B. Seale and R.E. Spieler. 1991. Waterbourne lead affects feeding abilities and neurotransmitter levels of juvenile fathead minnows (Pimaphales promelas). Aquatic Toxicology 21: 71-80.

Weber, D.N. and R.E. Spieler, 1994. Behavioral mechanisms of metal toxicity in fishes. In Aquatic Toxicology., CRC press, Boca Raton, FL. Pgs 421-67.

Weir, P.A., and C.H. Hine, 1970. Effects of various metals on behavior of conditioned goldfish. Archives of Environmental Health 20: 45-51. 
Weis, J.S. and P. Weis, 1995. Swimming performance and predator avoidance by mummichog (Fundulus heteroclitus) larvae after embryonic exposure to methylmercury. Canadian Journal of Fisheries and Aquatic Science 52: 2168-2173.

Werner, E.E. and D.J. Hall, 1974. Optimal foraging and the size selection of prey by the bluegill sunfish (Lepomis macrochiris). Ecology 55: 1042-1052.

Werner, E.E. and D.J. Hall, 1988, Ontogenetic habitat shifts in bluegill: the foraging ratepredation risk trade off. Ecology 69: 1352-1366.

Wiener, J.G. and D.J. Spry. 1996. Toxicological significance of mercury to freshwater fish. In Environmental Contaminants in Wildlife, pgs297-339. CRC press, Boca Raton, FL.

Windom, H.L. and D.R. Kendall, 1979. Accumulation and biotransformation of mercury in coastal and marine biota. Pgs 303- 323 In: The Biogeochemistry of Mercury in the Environment, J.O. Nriagu ed. Elsevier/North-Holland Biomedical press, Amsterdam.

WHO, 1976. Mercury. World Health Organization, Geneva.

Zar, J., 1996. Biostatistical analysis $3^{\text {rd }}$ ed. Prentice Hall, Upper Saddle River, NJ.

Zhou, T. and J.S. Weiss, 1998. Swimming behavior and predator avoidance in three populations of Fundulus heteroclitus larvae after embryonic and/or larval exposure to methylmercury. Aquatic Toxicology 42: 131-148.

Zhou, T., D.J. Rademacher, R.E. Steinpreis, J.S. Weis. 1999. Comparative Biochemistry and Physiology C 124: 287-94. 
Appendix A: Figures 


\section{TOXICANT EXPOSURE}

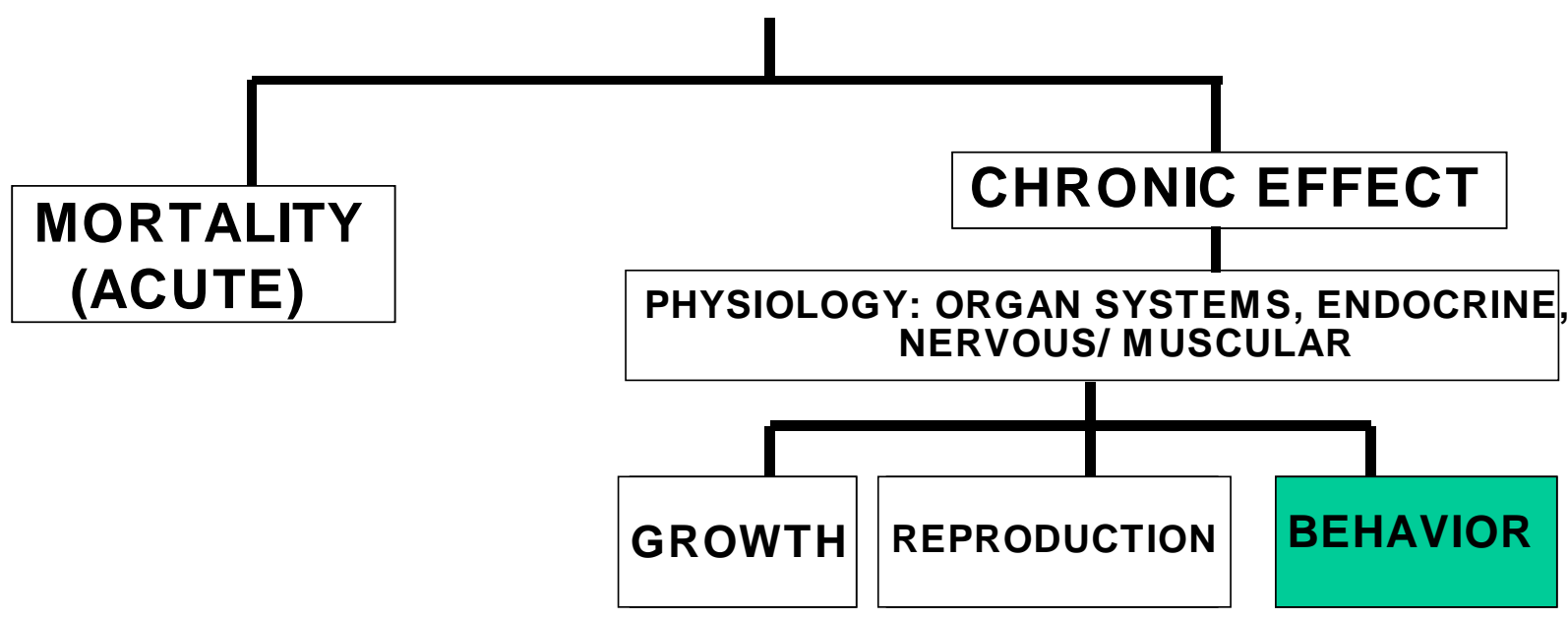

Fig. 1. Potential alterations in individuals after exposure to a toxicant 
Fig. 2. Potential ways toxicants can disrupt the steps leading to prey consumption

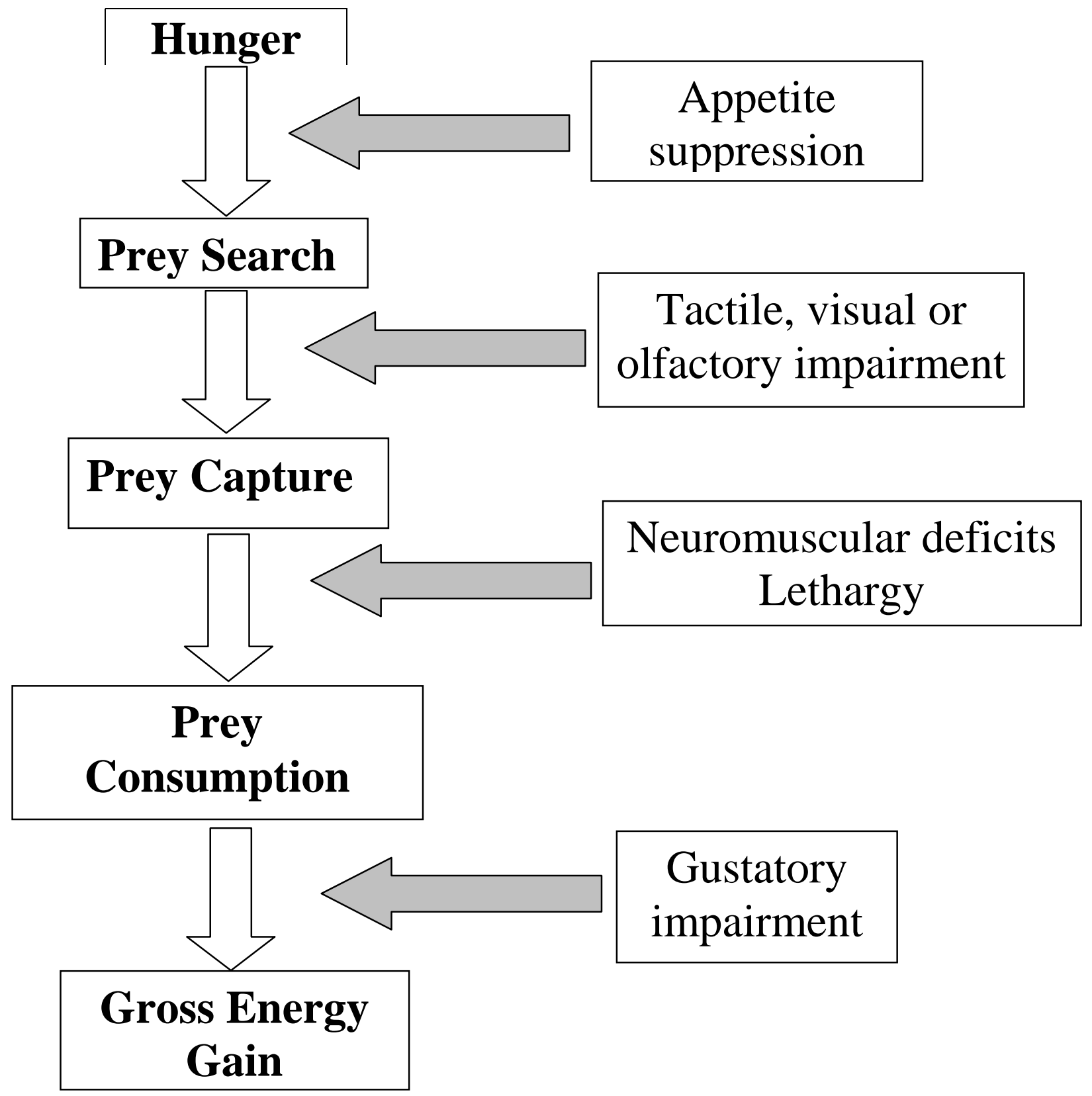


Fig. 3. Ways in which experience, through learning influences habitat choice, prey search within the habitat, and prey capture.

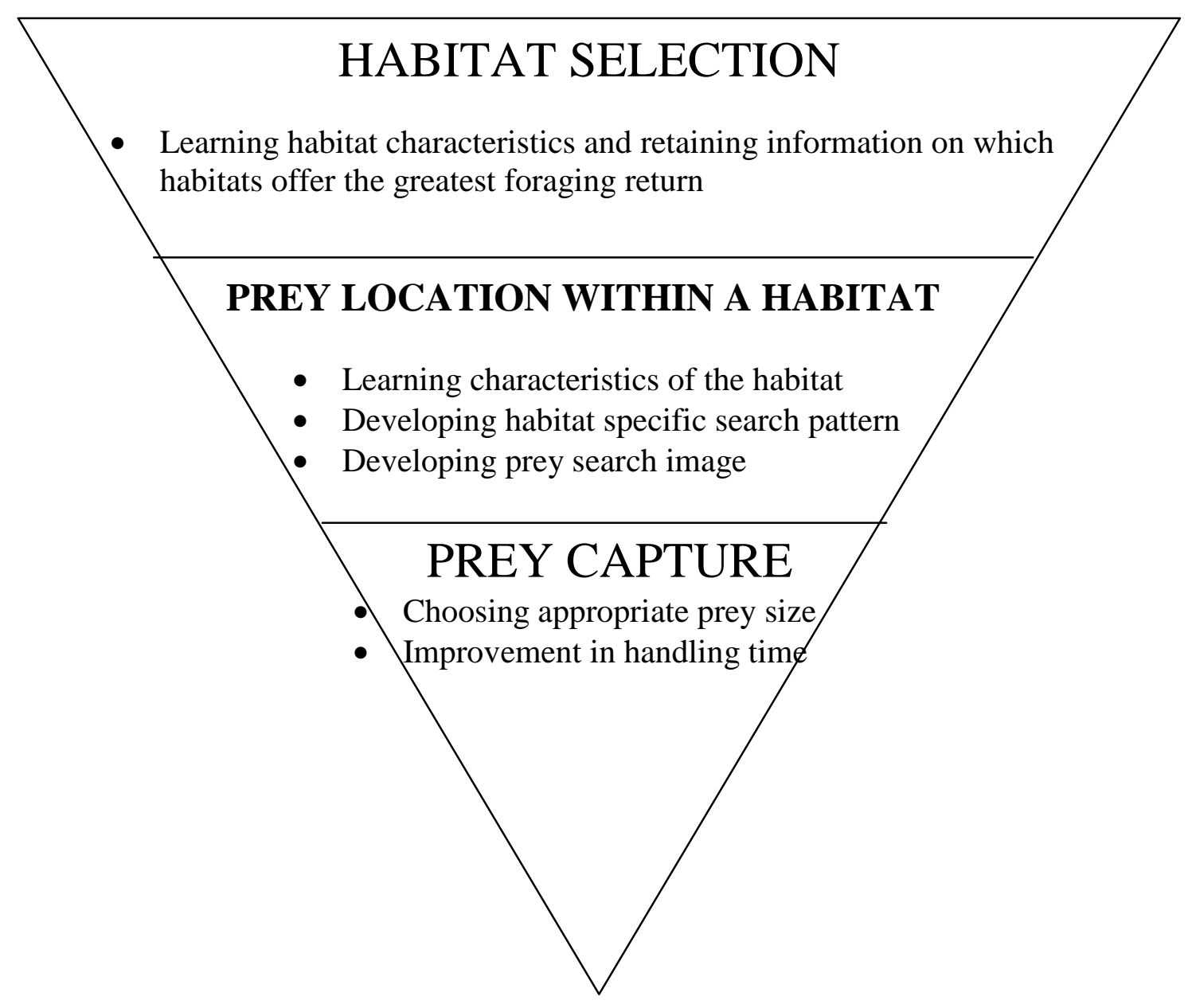


Figure 4. Diagram of the experimental feeding habitats for experiments one and two.

Fig. 4 (a) Experiment one

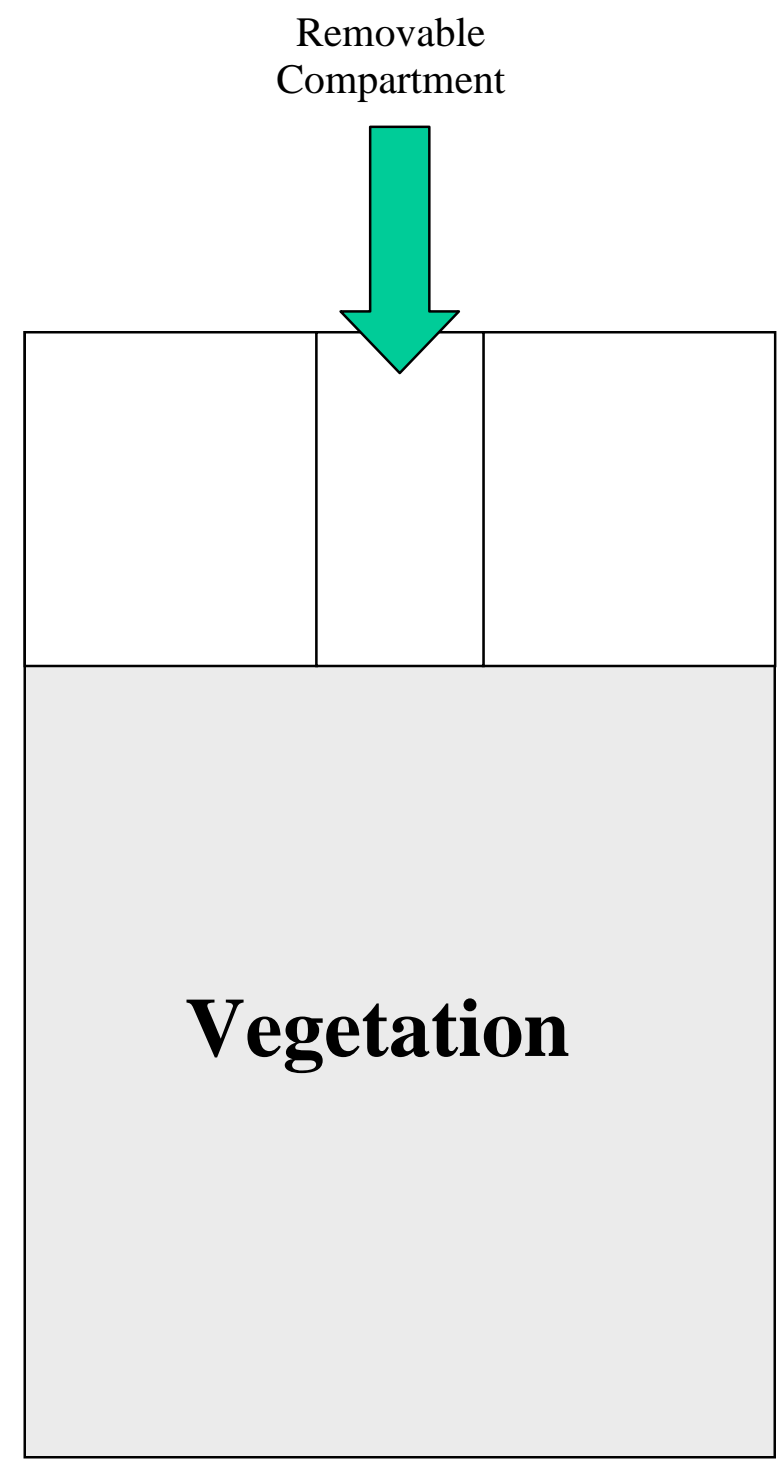

Fig. 4(b) Experiment two

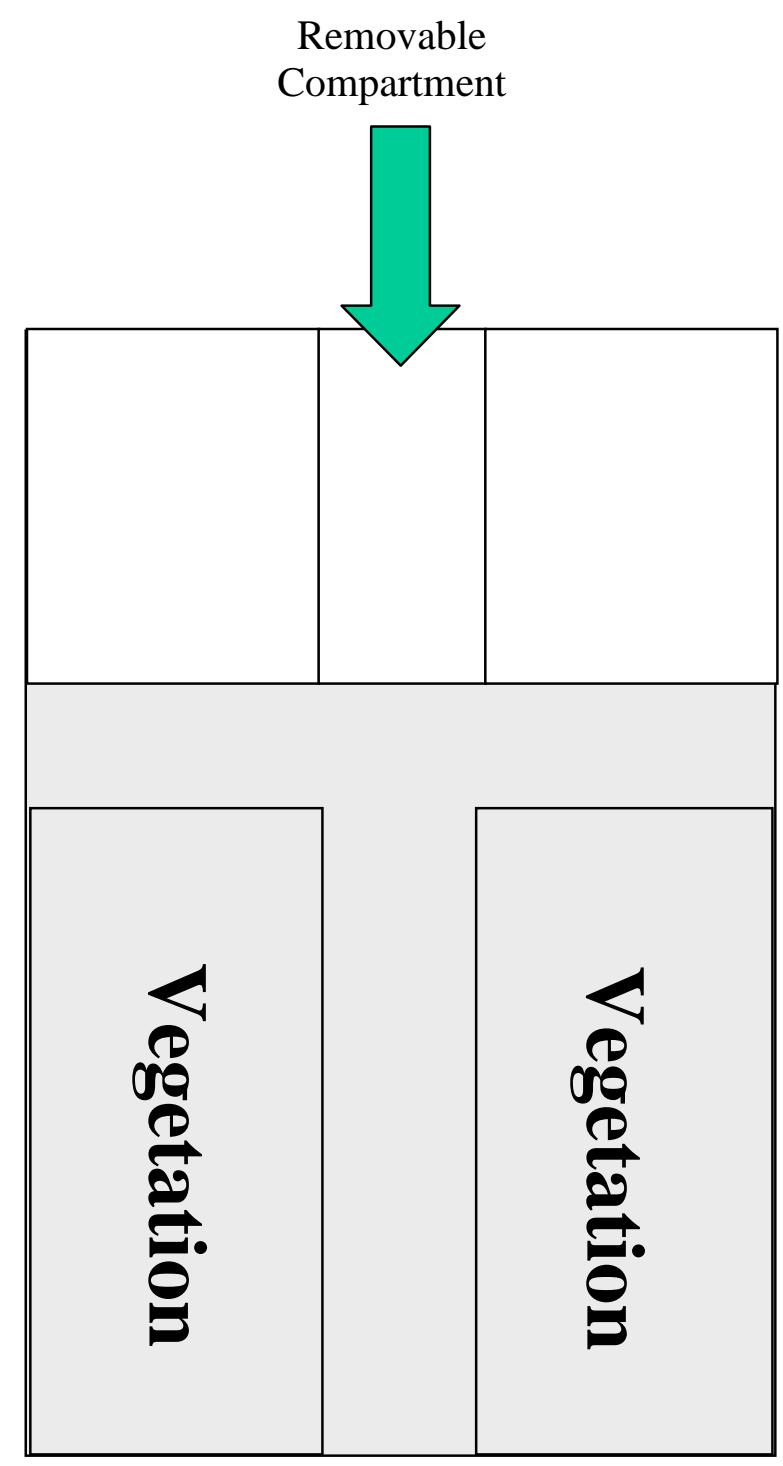


Fig. 5. Number of worms encountered by control and treatments after 1 minute. Each data point represents the mean and SE for each group for that day. An $(*)$ indicates a significant difference from the control.

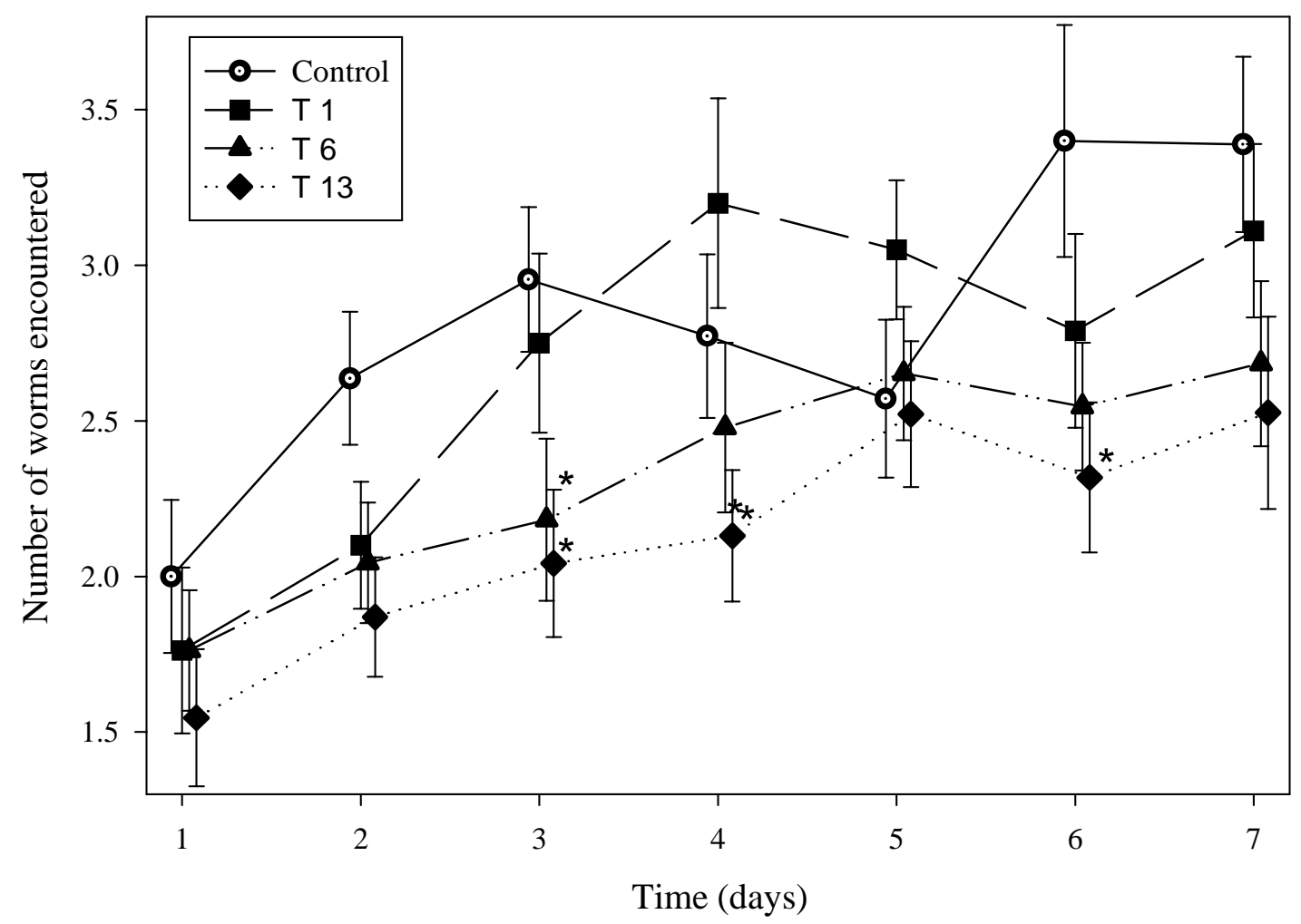

Figure 5 
Fig. 6. Number of worms encountered by control and treatments after 2 minutes. Each data point represents the mean and SE for that group for that day. An (*) indicates a significant difference from the control.

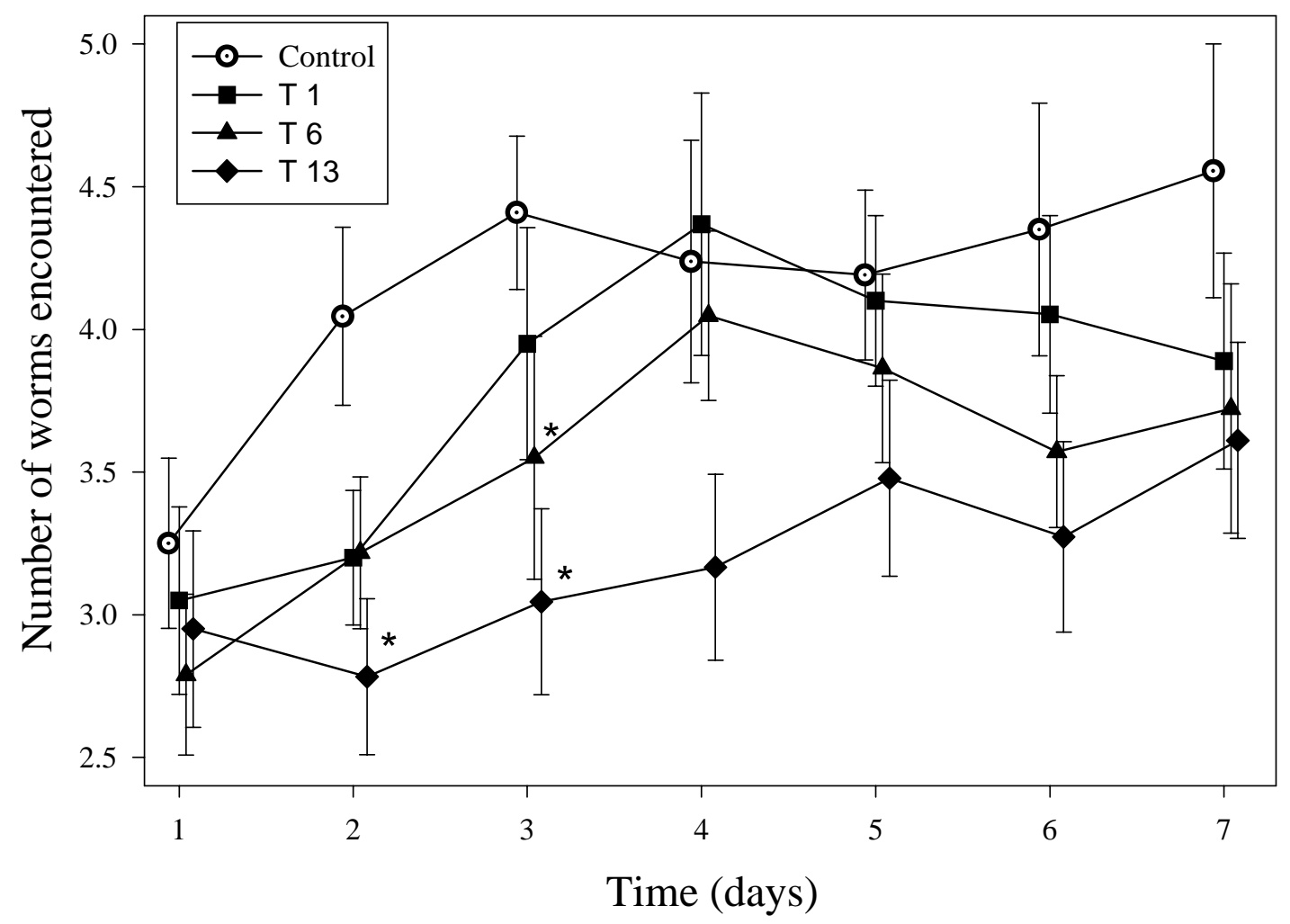

Figure 6 
Fig. 7. Number of worms encountered by control and treatments after 3 minutes. Each data point represents the mean and SE for that group for that day. An $\left(^{*}\right)$ indicates a significant difference from the control.

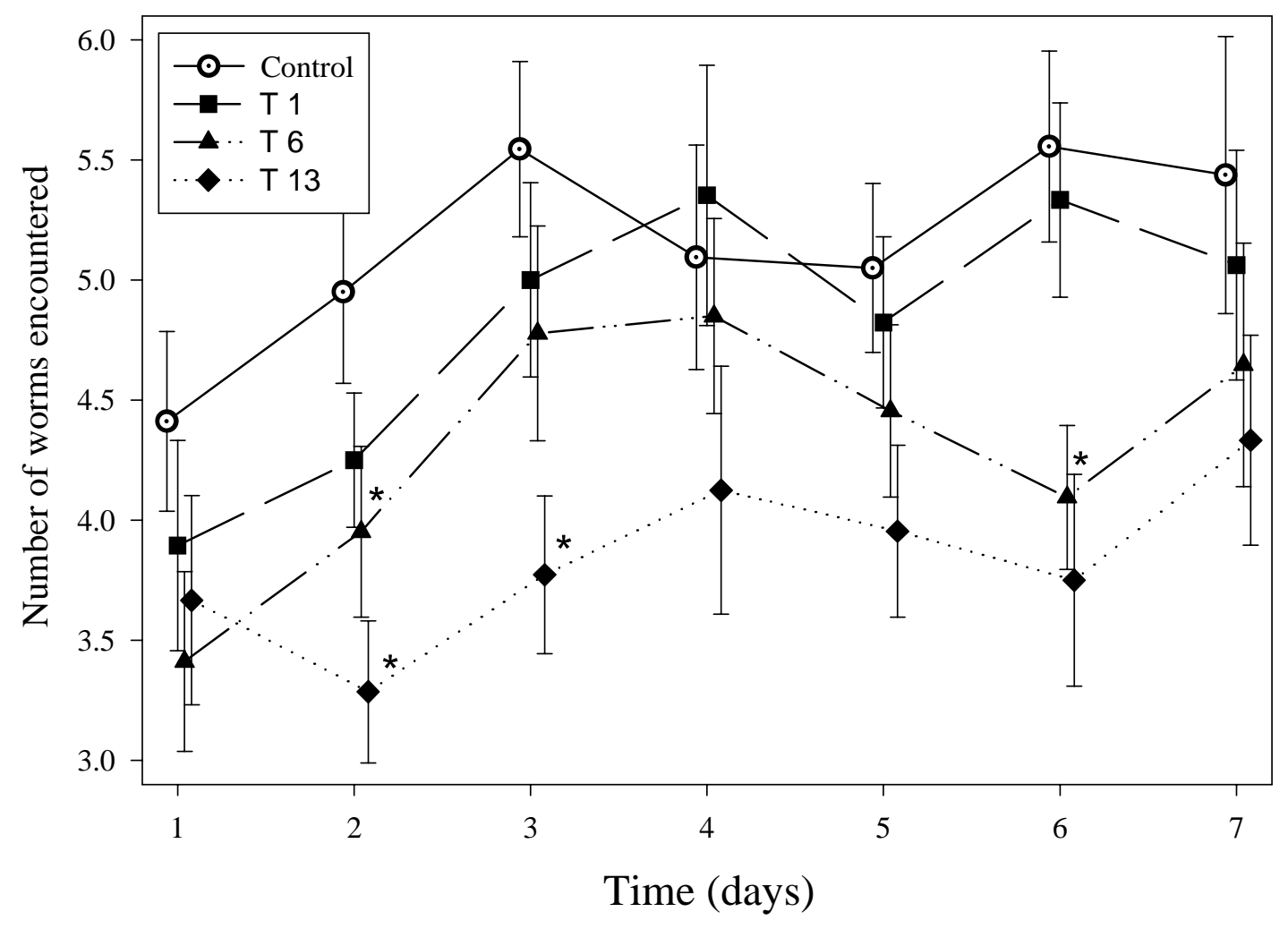

Figure 7 
Fig. 8. Maximum encounters (for 2 and $3 \mathrm{~min}$ ) over the $7 \mathrm{~d}$ trial period for each treatment. Each bar represents the mean and SE of the two best performances by each fish over the 7-d trial period. Bars with different letters are significantly different.
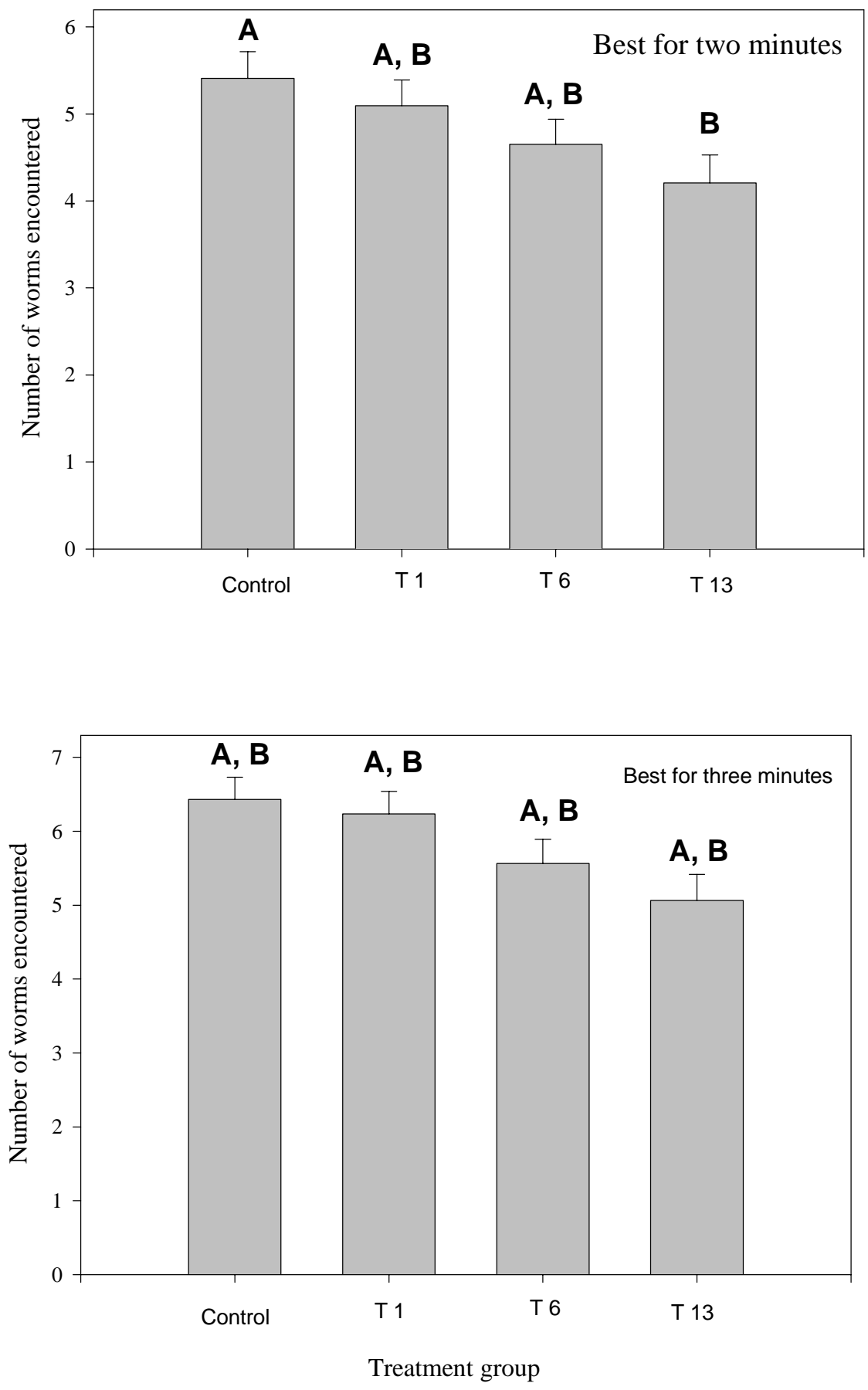
Fig. 9. Time to three encounters over the seven day trial period. Each data point represents the mean and SE for that group for that day. An (*) indicates a significant difference from the control.

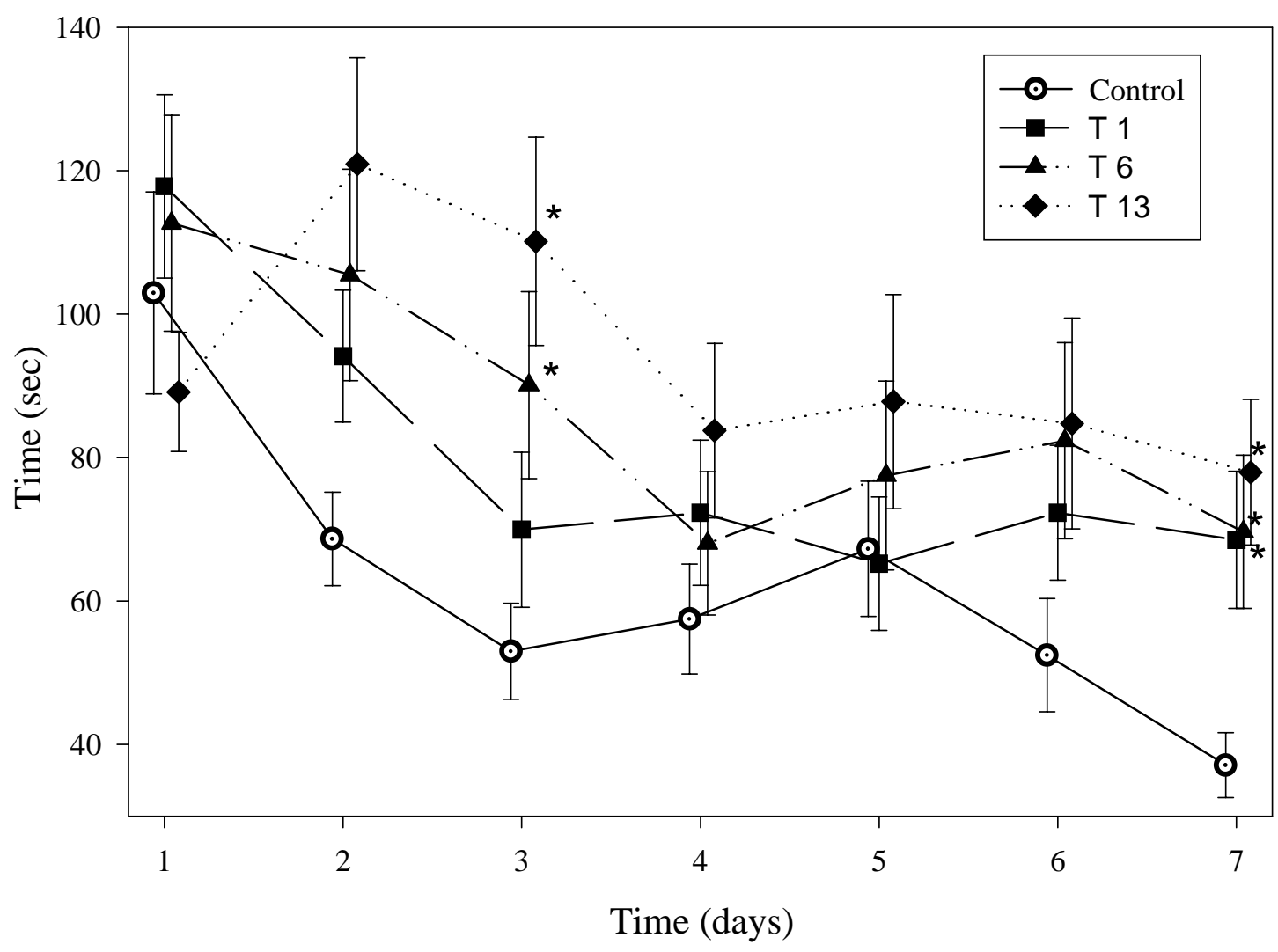

Figure 9 
Fig. 10. Time to four encounters over the seven day trial period. Each data point represents the mean and SE for that group for that day. An (*) indicates a significant difference from the control.

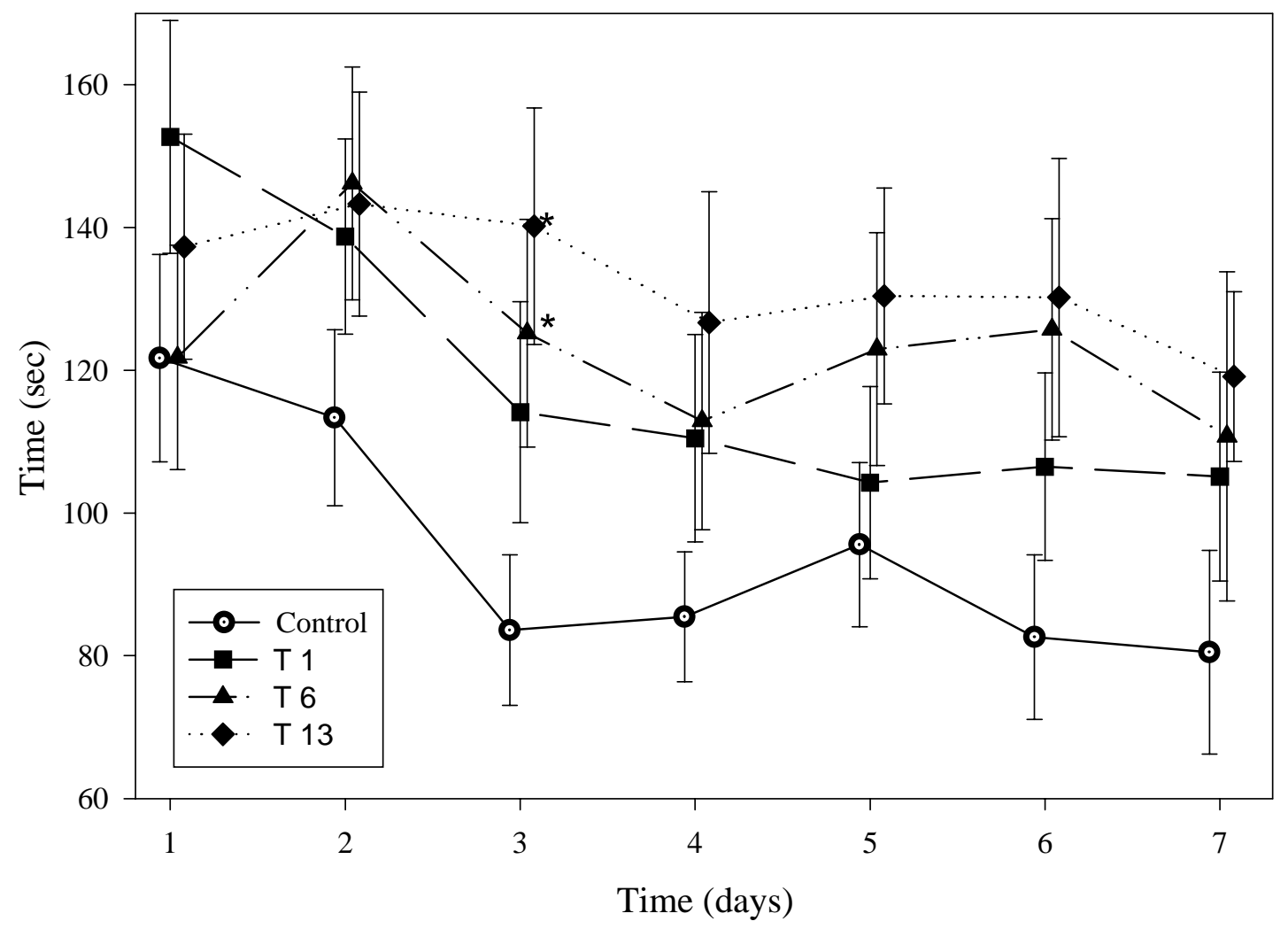

Figure 10 
Fig. 11 Shortest time to three and four encounters for each group. Each bar represents a treatment average of individual fish's two shortest times to three or four prey encounters over the $7 \mathrm{~d}$ trial period. Data log transformed for equal variance. Bars with different letters indicate significant differences.
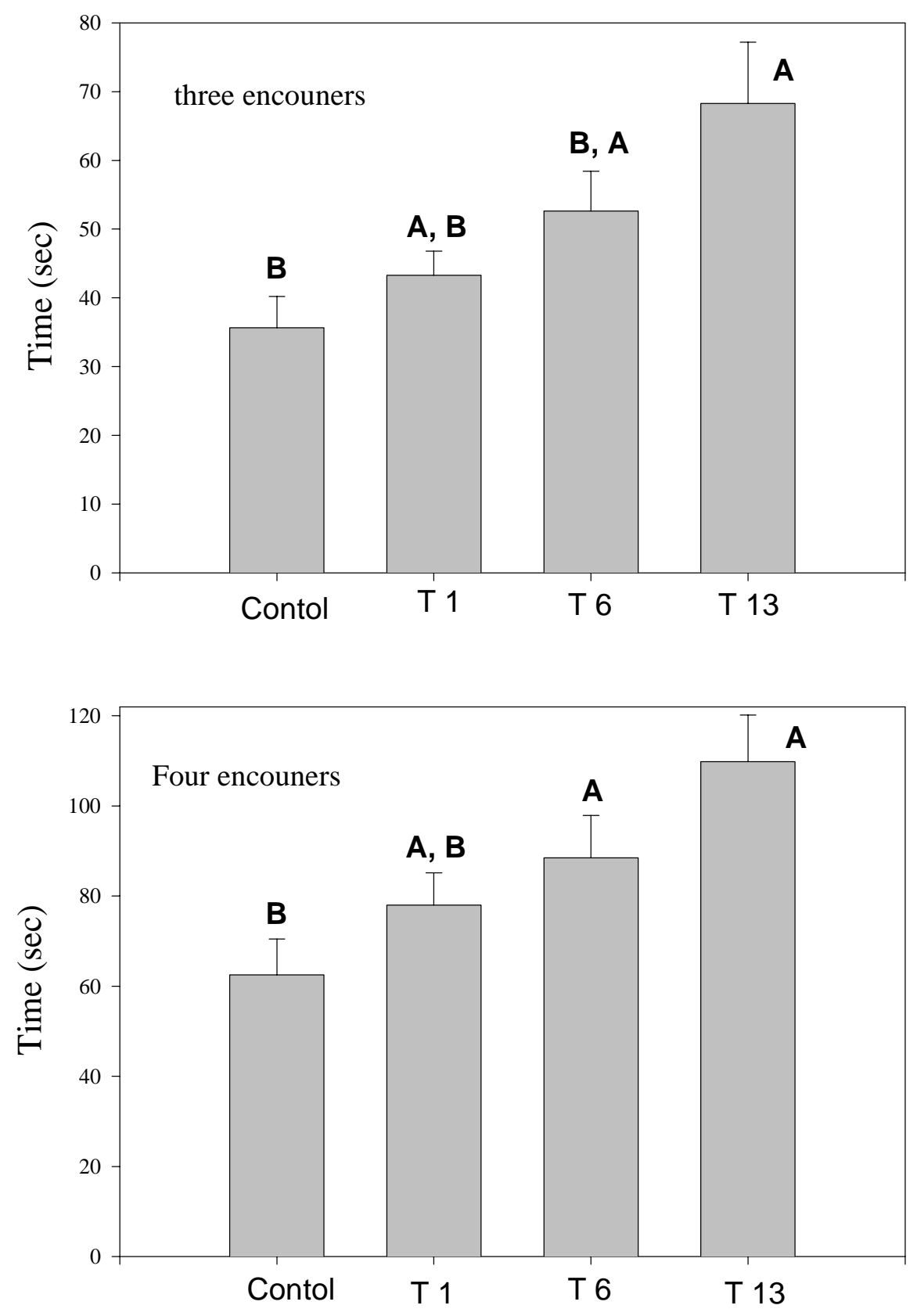

Treatment group 
Fig. 12. Performance distribution of control $(n=22)$ and $T 13(n=24)$ for time to four encounters. Within treatments the mean of the last four trial days was used for grouping individual fish. The grouping $>220$ included fish who failed to encounter four worms.

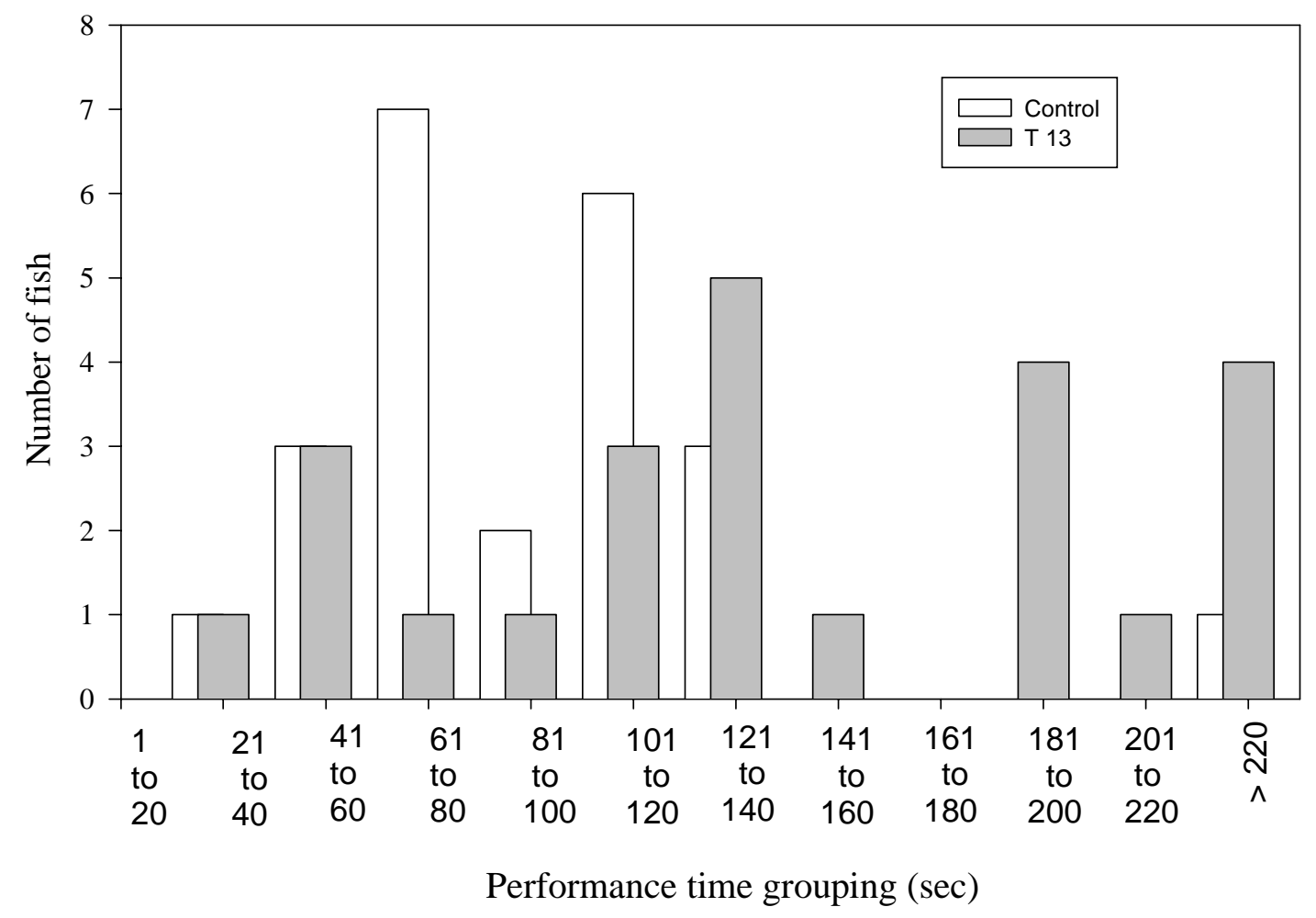

Figure 12 
Fig. 13. Performance distribution of control $(n=22)$ and $T 6(n=23)$ for time to four encounters. Within treatments, the mean of the last four trial days was used for grouping individual fish. The grouping > 220 included fish who failed to encounter four worms.

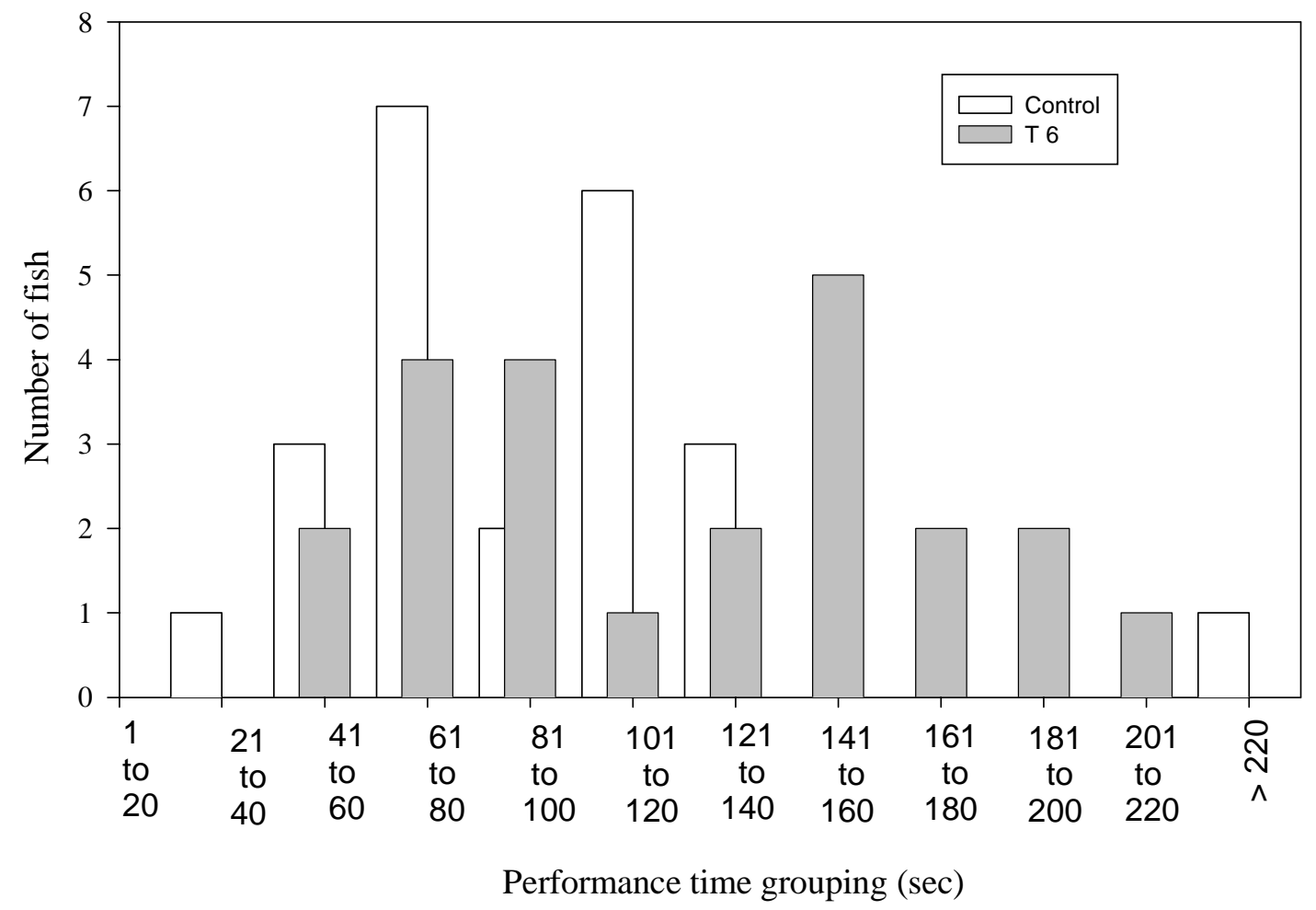

Figure 13 
Fig. 14. The relationship between pause time and the time until 3 worms are encountered. Each data point represents the 7 day average of the time to three encounters and the 7-day average of the pause time until three encounters.

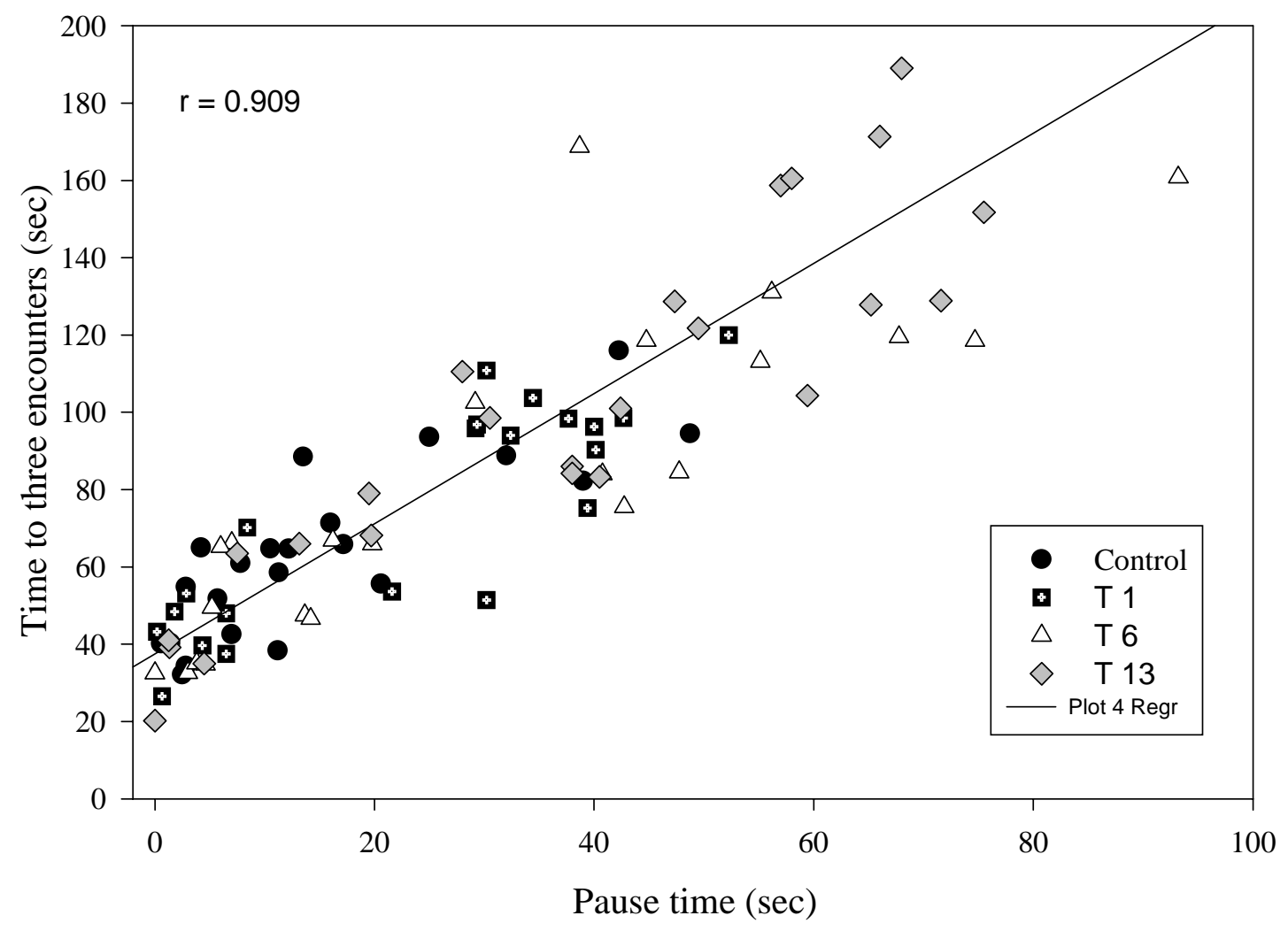

Figure 14 
Fig. 15 The relationship between pause time and the time until 4 worms are encountered. Each data point represents the 7 day average of the time to four encounters and the 7-day average of the pause time until four encounters.

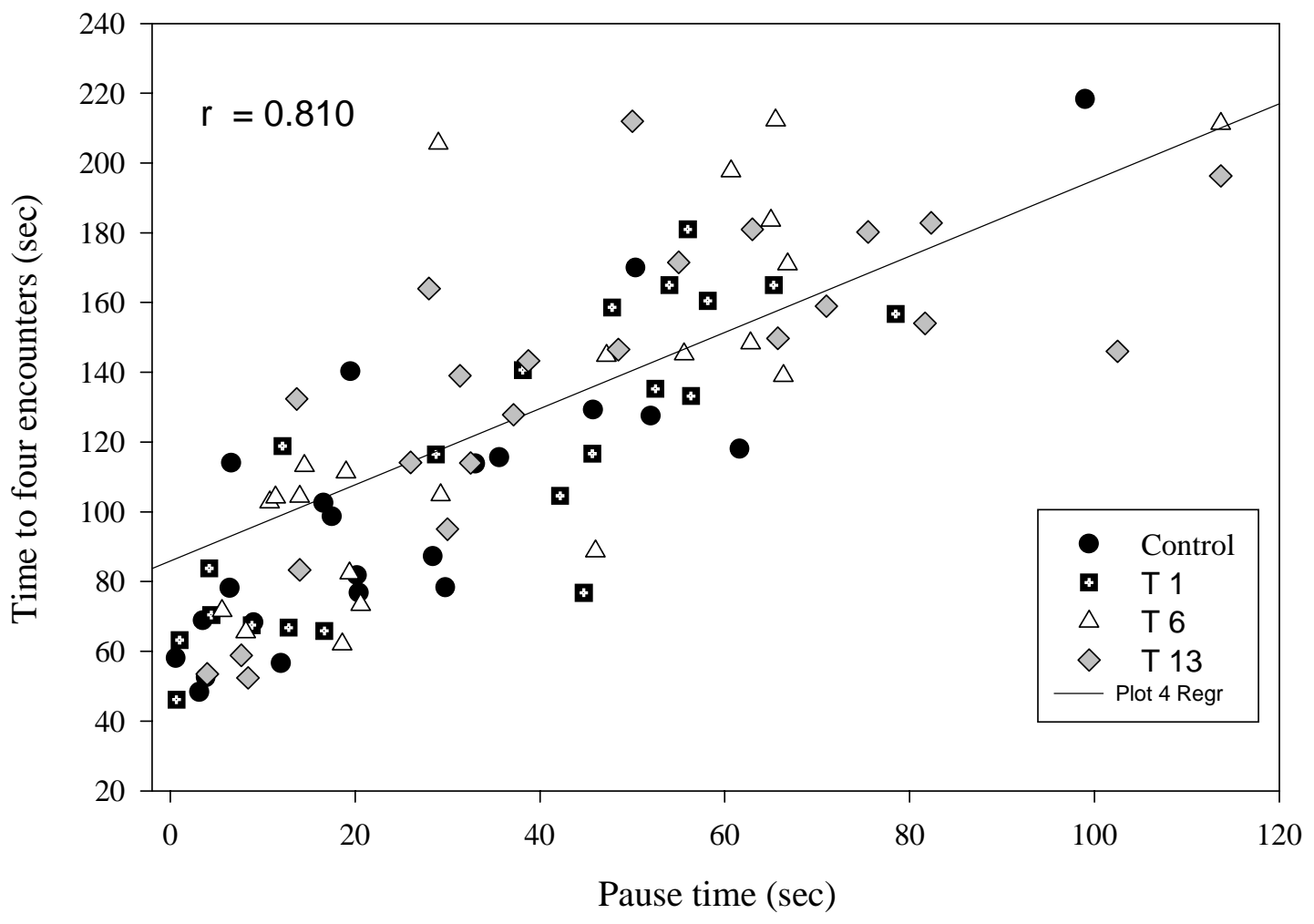

Figure 15 
Fig. 16. Average daily pause time (mean and SE) until three and four worms were encountered. Bars with different letters are significantly different.
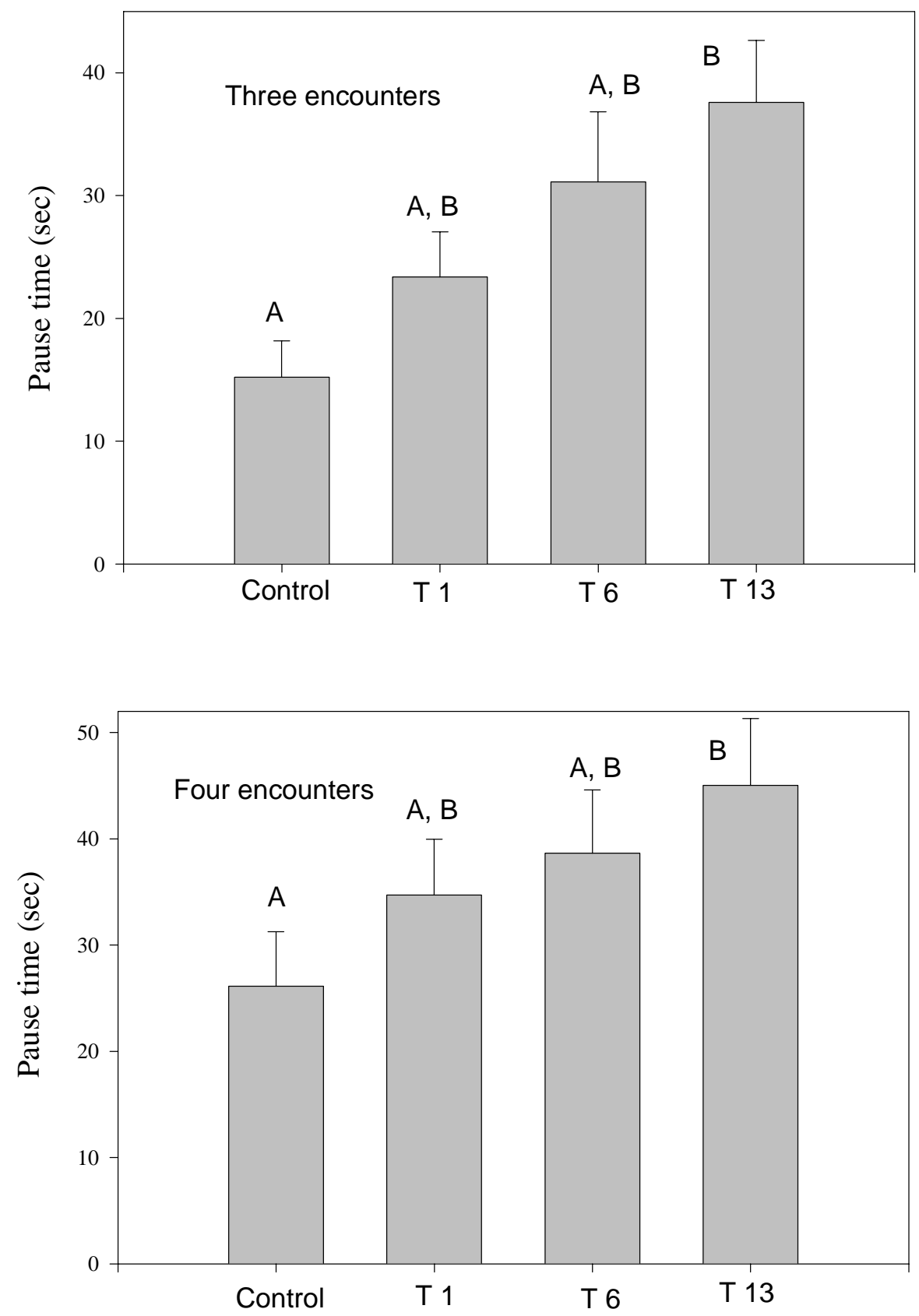

Figure 16 
MARK A. GRIPPO

301 Loudon Rd. Apt. 322

Blacksburg, VA 24060

\section{$\underline{\text { EDUCATION }}$}

- Master of Science in biology (concentration in ecology and environmental studies) from Virginia Polytechnic Institute- 5/2001

- Bachelor of Science in biology from the College of William and Mary- 5/ 1996

- Participated in the Virginia Institute of Marine Science tidal wetlands workshop- 1997

\section{EXPERIENCE}

- Virginia Marine Science Museum (part-time)- 3/97 - 8/98

- Education staff- duties included researching, writing, and giving educational

- Virginia Marine Science museum (part-time)- volunteer 5/97 -8/97; employee 9/97- 8/98

- Water quality technician -

- Old Dominion University Oceanography Department (part-time)- 10/97 to 2/98

\section{PROFESSIONAL ACTIVITIES}

- Received grant from Graduate Research and Development Program - spring 2000

- Member Society of Environmental Toxicology and Chemistry 